\title{
$\$$ Research Square

\section{Upset Protrusion Joining (UPJ) Characteristics of Cast AM60 Magnesium Alloy to Join With Dissimilar Material}

Nicholas Andreae

McMaster University

Dharmendra Chalasani ( $\square$ chalasanidharmendra@gmail.com )

University of New Brunswick Fredericton https://orcid.org/0000-0002-1550-9219

Mukesh K. Jain

McMaster University

\section{Research Article}

Keywords: Magnesium alloys, Aluminum alloys, Dissimilar Materials Joining, Upset Protrusion Joining, Resistance Heating, Mechanical Joint

Posted Date: September 28th, 2021

DOl: https://doi.org/10.21203/rs.3.rs-922851/v1

License: (9) This work is licensed under a Creative Commons Attribution 4.0 International License. Read Full License

Version of Record: A version of this preprint was published at The International Journal of Advanced Manufacturing Technology on January 31st, 2022. See the published version at https://doi.org/10.1007/s00170-021-08563-5. 


\title{
Upset Protrusion Joining (UPJ) Characteristics of Cast AM60 Magnesium Alloy to join with Dissimilar Material
}

Nicholas Andreae ${ }^{\mathrm{a}}$, Dharmendra Chalasani ${ }^{\mathrm{a},{ }^{*}, \text { Mukesh Jain }}{ }^{\mathrm{a}}$

${ }^{a}$ Department of Mechanical Engineering, McMaster University, Hamilton, Canada, L8S 4L7

\begin{abstract}
Magnesium alloys have a significant benefit over the steel and aluminum alloys in manufacturing of components for many automotive and structural applications because of their extreme lightweight, low density, and high strength to weight ratio. However, one of the glaring impediments to the success of steels, aluminum, and magnesium-based multi-material integration for automotive industries is the ability to join these materials together without any cracking and corrosive damages during a performance. The present work aims to demonstrate a cost-effective, novel, and versatile joining technique, named Upset Protrusion Joining (UPJ), to mechanically and rapidly (1-2 seconds) join die-cast AM60 alloy to aluminum alloy sheet and evaluate its UPJ characteristics. Cast Mg plate has a cylindrical protrusion $(11 \mathrm{~mm}$ diameter and $14 \mathrm{~mm}$ height) emanated perpendicular to its flat surface, and an aluminum sheet has a hole that accommodates the protrusion. $\mathrm{Mg}$ and $\mathrm{Al}$ alloy components are then clamped together, electrically heated, and compressed perpendicular to the protrusion axis. During compression, the protrusion expanded circumferentially to fill the hole as well as the region above the hole, and entrapped the Al sheet between the deformed (in a mushroom shape) head and the Mg plate. The effect of different UPJ process parameters such as applied current, current duration, compression loading rate, and compression distance is studied. The process demonstrated repeatability at given process conditions, and optimum process parameters were identified that produce visibly good joints (defect-free) and sufficient joint strengths when tested in the lap-shear mode under uniaxial tension. AM60 alloy showed a great promise as a candidate alloy to suit the UPJ method to adapt to automotive and other industrial manufacturing units to join with dissimilar wrought $\mathrm{Al}$ alloy sheets.
\end{abstract}

Keywords: Magnesium alloys; Aluminum alloys; Dissimilar Materials Joining; Upset Protrusion Joining; Resistance Heating; Mechanical Joint

\footnotetext{
* Corresponding author. Tel: +1-812-844-7110; E-mail: chalasanidharmendra@gmail.com

** C. Dharmendra is currently at Uniformity Labs, Inc., 41400 Christy Street, Fremont, CA, USA, 94538
} 


\section{Research Highlights}

$>$ Developed and evaluated an enabling technology for dissimilar metal joining

$>$ Commissioned a lab-based Upset Protrusion Joining (UPJ) process equipment

$>$ Integrated resistance heating and mechanical loading systems for hot compression

$>$ Studied the effect of UPJ parameters to join die-cast AM60 with wrought Al alloy

$>$ Good quality joints were made, and the joints performance was reported

\section{Introduction}

Environmental pollution via greenhouse gas emissions is the primary concern for the transportation industry, such as automobile manufacturers. Reducing the weight of the vehicles is one of the most cost-effective strategies to improve mileage, thereby decreasing the fuel consumption and $\mathrm{CO}_{2}$ emissions. Magnesium $(\mathrm{Mg})$ and its alloys are being developed for use as structural components in the automobile and aerospace industries due to their lightweight, high elastic modulus, strength to weight ratio, castability, damping capacity, electromagnetic interference shielding, heat dissipation capability, ability to withstand shock loads, and recyclability $[1,2]$. Aluminum $(\mathrm{Al})$ and its alloys are widely used in the automotive industry because of their low density, high specific strength, good formability and corrosion resistance, and attractive appearance $[3,4]$.

A significant reduction in the weight of the vehicles could be achieved only with the adaption of a multi-material solution to the structural chassis and body components. While $\mathrm{Mg}$ and $\mathrm{Al}$ alloys have demonstrated the ability to provide substantial weight reductions compared to steel [5], one of the significant obstacles to the success of such an integration is joining these materials together without any corrosive damages during the performance. Joining aluminum to the steel components has been reasonably successful in recent years [6,7]; however, for the automotive industry, there is a greater need for a joining process to join $\mathrm{Mg}$ alloys with $\mathrm{Al} / \mathrm{steel} /$ other dissimilar components at high process speeds. Also, it is imperative to develop techniques that work well with the cast alloys due to the high cost and formability issues with wrought magnesium alloys.

Fusion welding of $\mathrm{Mg}$ and $\mathrm{Al}$ pose a problem with the hard and brittle intermetallic phases (IMPs) such as $\mathrm{Mg}_{17} \mathrm{Al}_{12}$ and $\mathrm{Mg}_{2} \mathrm{Al}_{3}$ [8,9], despite the addition of interlayers [10] Solid-state joining processes such as friction stir welding (FSW) [11-14] and diffusion bonding 
[15-19] employs low heat input to decrease the temperature. However, it was found that the precipitation of IMPs in the microstructure is inevitable. Adhesive bonding $[20,21]$ is one of the successful joining techniques for magnesium. However, the unstable oxide layer that forms very quickly on magnesium can result in premature adhesion failure during material exposure to a corrosive environment. Pre-treatments and coatings help, but the adhesive bond is then limited to the adhesion of the coating to the magnesium alloy. Bolts and fasteners can be used to join dissimilar materials where the feasibility of welding is not good. However, it increases the production cost and exacerbates the potential problems of galvanic corrosion. Magnesium's highly anodic properties cause corrosion when electrically bonded to less anodic metals. In $\mathrm{Mg}$-steel joints, galvanic corrosion between the steel rivet and the magnesium components is another concern.

The limitations mentioned above clearly indicate the imperative for the automotive industries for a suite of joining methods that can provide practical, robust, and cost-effective joining techniques. Fiat Chrysler Automobiles (FCA, USA) has patented a novel technology concept [22] called Upset Protrusion Joining (UPJ) that shows the promise of a practical solution to join magnesium castings to each other and to wrought materials, as well as to dissimilar materials, without the additional galvanic corrosion concerns created by rivets and fasteners. Unlike currently available commercial joining processes, the UPJ process relies on a very robust mechanical joint. In the author's previous work [23], the design and development of a UPJ system and preliminary results were presented, demonstrating the proof-of-concept. Briefly, the UPJ process involves a cast plate that has a cylindrical protrusion (magnesium alloy in the present work) and a sheet of dissimilar material (cast or wrought) with a hole to fit the protrusion as shown in Fig. 1(a). After clamping, the protrusion is rapidly heated via resistance heating (using electrodes) followed by rapid deformation (uniaxial compression) by applying load (electrode is also a die) on the top face of the protrusion. Under the application of load, protrusion undergoes plastic deformation. It expands radially above the hole in the sheet component such that the sheet is locked between the deformed protrusion and the cast part, as shown in Figs. 1(b) and (c). The UPJ process is genuinely a mechanical joining process without melting, phase transformations, or an interface formation between the joined materials. UPJ technique differs from the simple upsetting process due to the various constraints to the material (protrusion's) flow.

To the author's best knowledge, there is no information in the open literature on the thermo-mechanical deformation behavior of cast magnesium alloys under UPJ process conditions. Therefore, the work in this paper is a crucial initiative process to lay a platform for 
the UPJ process to achieve its potential towards the integration of multi-material structural components for the automotive industry. The main objective of the present work is to test the versatile UPJ process, study the effect of various process variables, and optimize the parameters to assess the capability of joining die-cast AM60 magnesium alloy with an aluminum sheet.

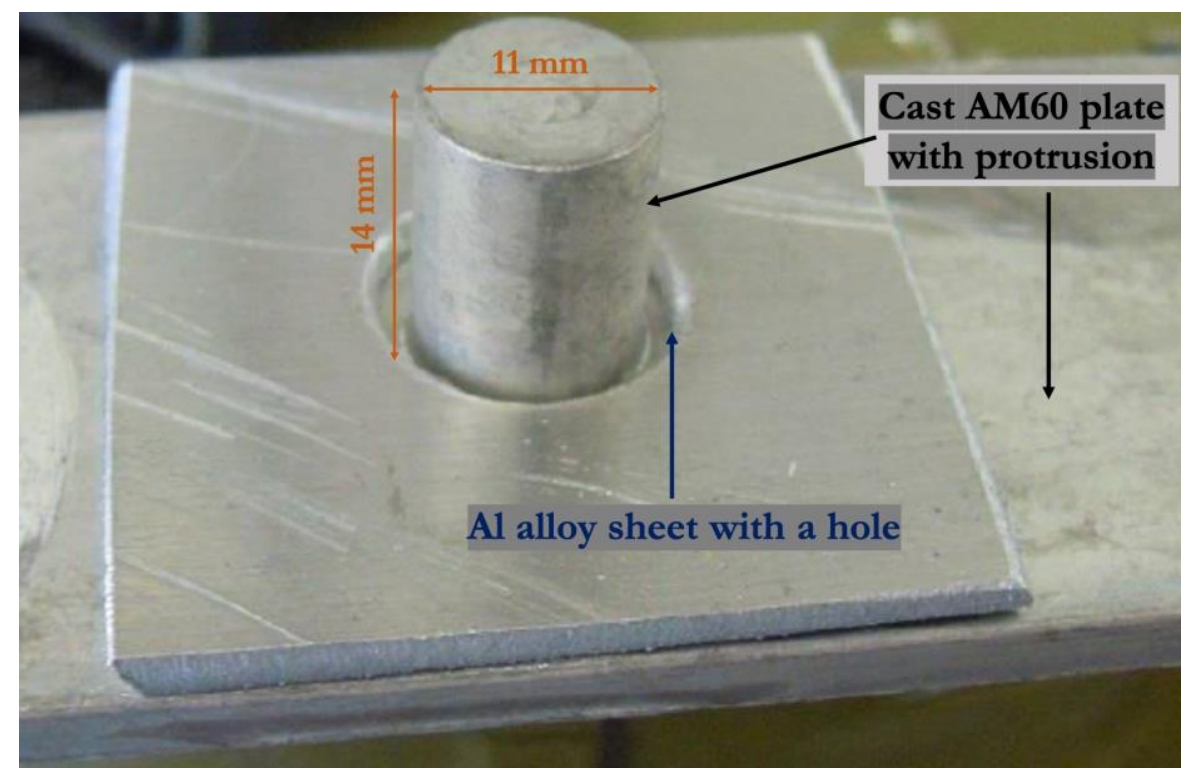

(a)

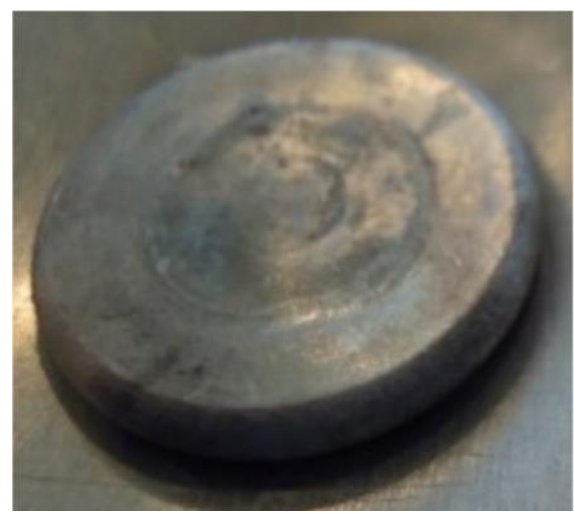

(b)

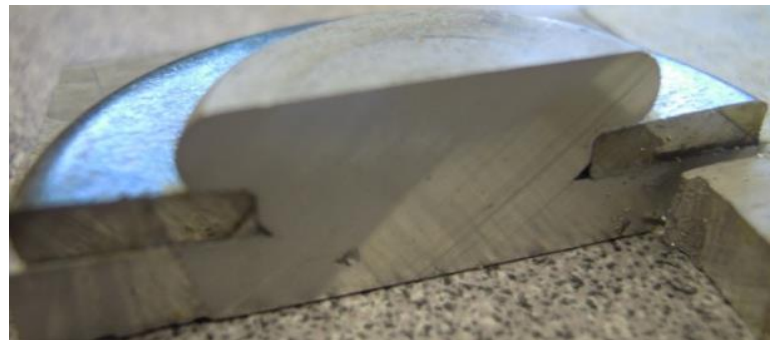

(c)

Fig. 1. (a) Schematic of the UPJ process; Cast AM60 component with a cylindrical protrusion and Al6061 aluminum sheet with a hole, (b) successful joint after the UPJ process, and (c) a sliced view of a UPJ joint showing an extensive shape change of the cylindrical protrusion in the form of a mushroomed head.

\section{Experimental work}

\subsection{Die-cast AM60 magnesium alloy with protrusion}

The nominal composition of the AM60 alloy is 5.5-6.5 wt.\% Al, 0.2-0.6 wt.\% Mn, and $\mathrm{Mg}$ as remainder. Fig. 2 shows the schematic of the AM60 plate with a cylindrical protrusion 
of $14 \mathrm{~mm}$ in height and $11 \mathrm{~mm}$ in diameter. The physical properties of a typical AM60 alloy are given in Table 1 [24]. The plates were die-cast at Dead Sea Magnesium, a subsidiary of Meridian Dynamics Corporation. The process used hydraulic systems to force molten metal into a die, and the casting was carried out with real-time control of injection shots with a cycle time of $45 \mathrm{~s}$. The oil inside the die surrounding the protrusion was set to $240^{\circ} \mathrm{C}$ with a melting temperature of the casting at $700^{\circ} \mathrm{C}$. The mold was filled in $20 \mathrm{~ms}$ at a hydraulic pressure of 300 bar. All original cast surfaces of the protrusion (flat top and bottom surfaces and cylindrical surface) were not machined for the UPJ experiments to retain the original fine grain structure of the surface region.

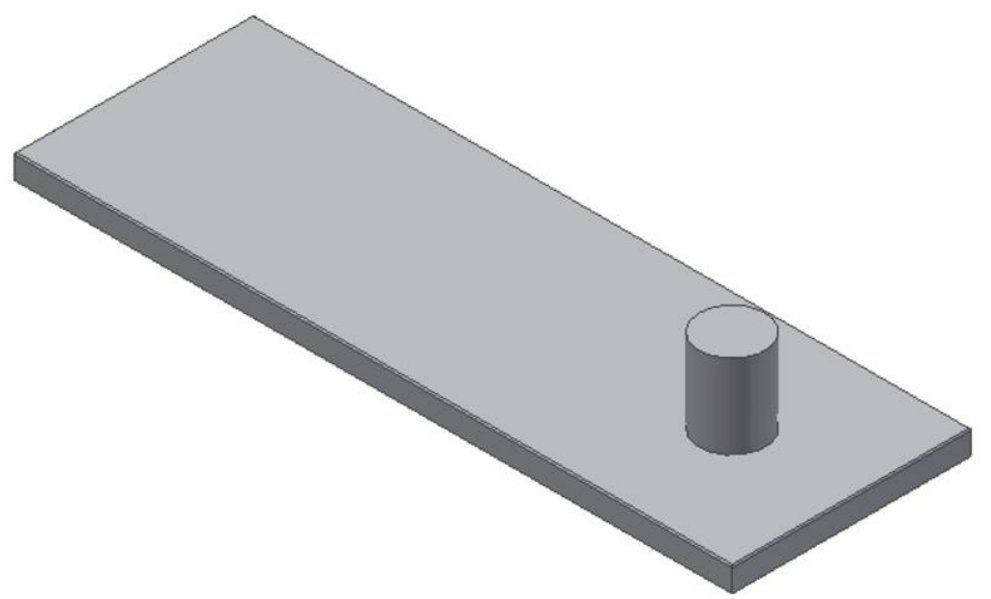

Fig. 2. A schematic of die-cast AM60 magnesium alloy test sample for creation of UPJ joints.

Table 1. Physical properties of AM60 alloy [24]

\begin{tabular}{cc}
\hline Property & Value \\
\hline Density & $1.80 \mathrm{~g} / \mathrm{cm}^{3}$ \\
Liquidus Temperature & $615^{\circ} \mathrm{C}$ \\
Solidus Temperature & $540^{\circ} \mathrm{C}$ \\
Coefficient of Linear Thermal Expansion $(\mathrm{CTE})$ & $25.6 \mu \mathrm{m} / \mathrm{m} . \mathrm{K}$ \\
Thermal Conductivity & $61 \mathrm{~W} / \mathrm{m} . \mathrm{K}$ at $20^{\circ} \mathrm{C}$ \\
Electrical Resistivity at $20^{\circ} \mathrm{C}$ & $0.0000120 \mathrm{ohm}-\mathrm{cm}$ \\
\hline
\end{tabular}

\subsection{UPJ system}

Details on the specific design features and development of the UPJ system were provided in the authors' earlier work [23]. A photograph of the UPJ test system and its principal components are shown in Fig. 3(a). Fig. 3(b) shows the testing area where the top electrode is in contact with the protrusion top. The electrode material should have low resistivity, sufficient strength and not undergo plastic deformation under applied load at its peak operating temperature. In this regard, a pure molybdenum electrode was used as the top electrode for 
resistance heating as well as a punch for the compressive deformation of the protrusion. Due to the larger contact area at the bottom, the probability of melting at the bottom electrode is less, and a copper electrode is used as it is less costly. 'Compression rate' indicates the speed of deformation, which is related to the strain rate. In the present work, compression is performed under high compression (or strain) rates to minimize the process time to develop UPJ as a rapid joining technique. 'Compression distance' is a UPJ process variable that is closely related to applied axial strain.

As the UPJ process involves applying heat and mechanical load to the protrusion to form it into a mushroomed protrusion head UPJ joint, there are two basic possibilities in terms of the sequence to heat and deform; concurrently or sequentially. Concurrent application of heat and load to the work-piece is a more efficient process than heating first and then applying the load. However, when the process is very rapid such as UPJ, the work-piece may not reach a suitable temperature, and the load (or strain) limit for a fracture may decrease, leading to a premature fracture. On the other hand, a sequential application of heating followed by plastic loading of the work-piece is not as efficient in terms of cycle time. But, the process does allow for greater control of heating parameters to achieve the desired forming temperature, including a time delay to ensure homogenization of temperature within the work-piece for enough 'plasticity' to attain the desired UPJ joint shape without cracking. It appears that there are no systematic studies in the literature related to the two cases noted above concerning the hightemperature simple upsetting process or any other processes. In the present work, the protrusions were heated and then compressed. 


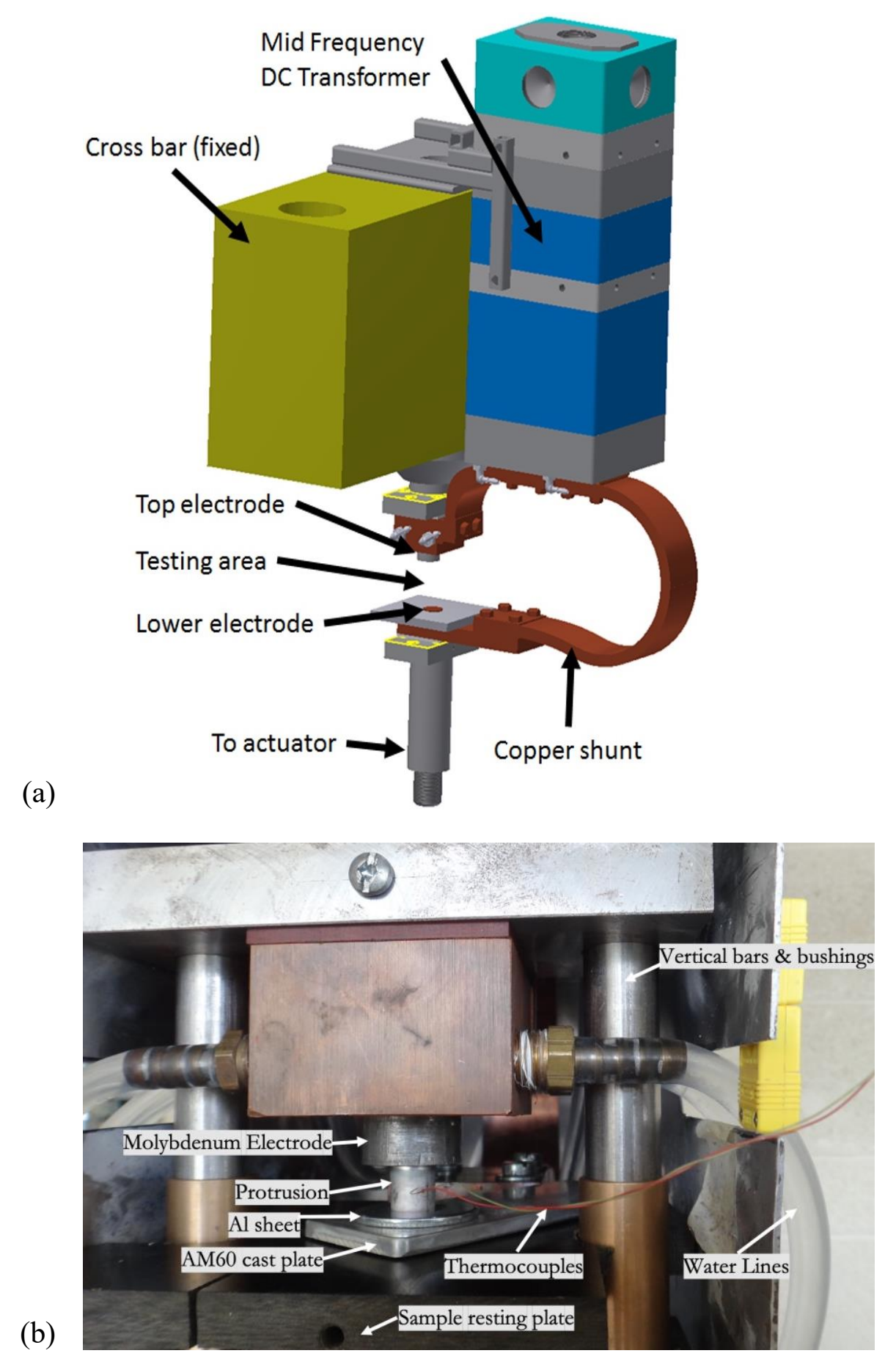

Fig. 3. (a) UPJ testing system and (b) testing area with the top electrode in contact with the top of the protrusion surface.

\subsection{Current Squared Time Profile (CSTP) and maximum current applied}

A ramp function was used to apply the current to the protrusion from 'zero' to a 'maximum current' over a duration (Fig. 4 shows schematic). During optimization trials, it was found that the ramp function prevented the noise, burning, and damage which are present with a constant current function. According to Eq. (1), the amount of energy entering a protrusion 
and thereby the temperature generates increases with the increase in the maximum current or duration [25].

$$
\text { Energy }=\int_{0}^{t_{f}} I^{2}(t) * R(t) d t
$$

where $I$ is applied current and $R$ is effective resistance. ' $I$ ' and ' $R$ ' can be varied with time variable $\mathrm{t}$, and $t_{f}$ is the total current duration (i.e., final time). In the present work, a parameter, Current Squared Time Profile (CSTP) was defined to account for different maximum currents and durations. Eqs. (2) and (3) express the CSTP variable, a product of the square of maximum current applied and the duration of applied current to heat the protrusion.

$$
C S T P=I_{\max }^{2} t
$$

where CSTP has units of $\mathrm{kA}^{2}$-s. This function was used for ramp functions. For example, increasing applied current from 0 to $11 \mathrm{kA}$ over 1 second produces a CSTP value of $121 \mathrm{kA}^{2}$-s. For constant CSTP tests, Eq. (4) can be expressed as follows:

$$
C S T P=I_{\max 1}^{2} t_{1}=I_{\max 2}^{2} t_{2}
$$

where $I_{\max 1}$ and $t_{1}$ and $I_{\max 2}$ and $t_{2}$ refer to two equivalent CSTP profiles.

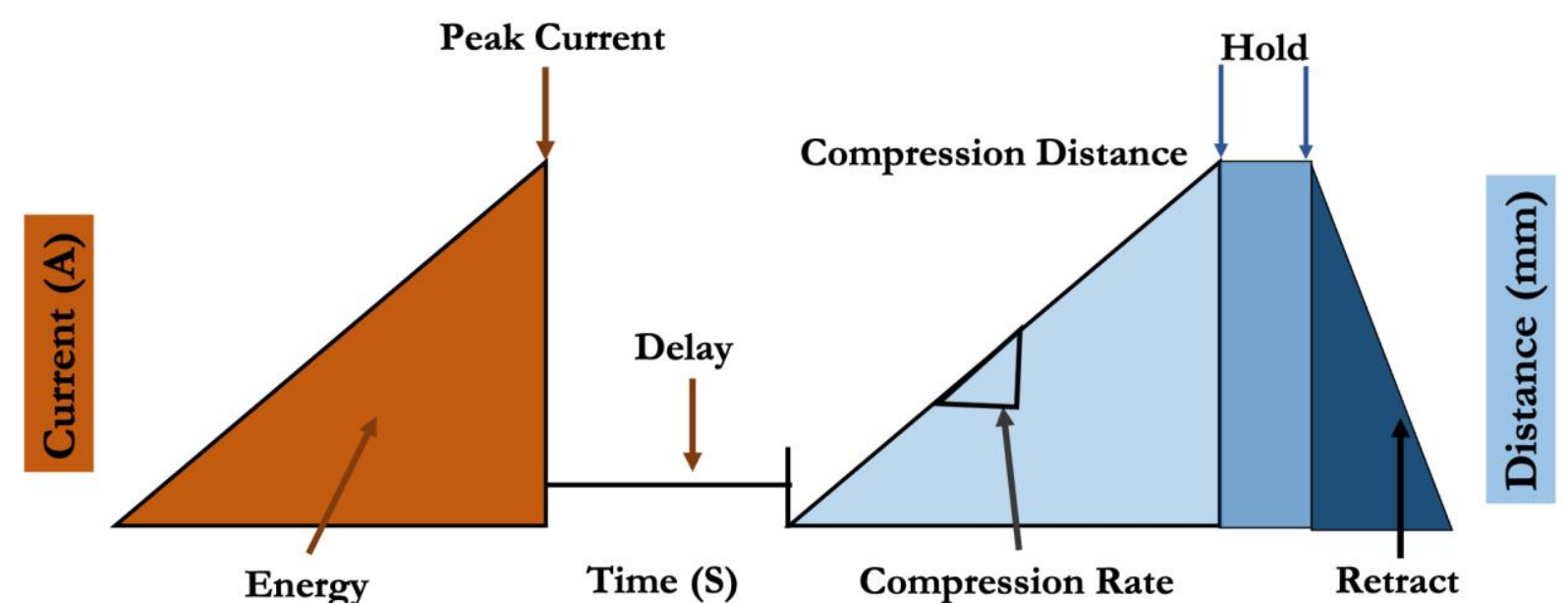

Fig. 4. UPJ process profile, i.e., heating (applied current) followed by the compression (electrode/punch displacement).

\subsection{Resistance heating experiments and temperature measurements}

To assess the heating characteristics such as temperature distribution and heating rates as a function of UPJ process parameters, only heating experiments (i.e., no plastic deformation) were performed while carrying out thermocouple-based temperature measurements in the protrusion regions (top, middle, and bottom). Thermocouples were mounted internally and externally on the protrusion, as shown in Fig. 5. No forming (i.e., plastic deformation) of the 
protrusion was performed in these experiments. A sheathed thermocouple is press-fitted into a tiny horizontal hole in the protrusion (hole axis being perpendicular to the protrusion axis) coated with a thermally conducting paste to measure the internal temperature of the protrusion during heating (Fig. 5(a)). In another setup, thermocouples were welded to the surface of the protrusion (Fig. 5(b)). Thermocouples were mounted at three different locations; $1 \mathrm{~mm}$ from the top of the protrusion, in the middle, and at the bottom of the protrusion corresponding to 1 $\mathrm{mm}$ from the upper surface of the bottom cast plate (Fig. 5(c)). A set of experiments were performed where the applied current was steadily increased from 0 to $15 \mathrm{kA}$ in increments of $1 \mathrm{kA}$ over different durations of fraction of a second. For example, the protrusion temperature nearly doubled (from $140^{\circ} \mathrm{C}$ to $280^{\circ} \mathrm{C}$ ) when the heating time was increased from 0.33 to 0.66 seconds for the same maximum current of $11 \mathrm{kA}$. When the protrusion was heated by different current profiles, the temperature profile is consistent in all experiments i.e., the hottest location was at the middle, followed by the bottom, and the top was the coldest. The lowest temperature at the top of the protrusion could conceivably come from conductive heat transfer from the top of the protrusion to the cooler top electrode.

Another set of experiments was conducted by changing the current duration and magnitude to maintain a constant CSTP. This was to investigate how the CSTP and maximum current affected the protrusion temperature before forming. The tests at similar CSTP values $\left(81 \mathrm{kA}^{2}-\mathrm{s}\right)$ were found to yield similar maximum temperatures from internal thermocouples, as shown in Table 2. The difference in the temperature from external and internal thermocouples may attribute to the skin effect (higher resistivity in the surface due to finer grain size that typically results from a high cooling rate during solidification). Also, for the external temperature measurement, a fine thermocouple welded directly to the protrusion surface. In contrast, the internal measurements were done using a tungsten encased thermocouple pressfit into a hole with thermal conducting paste. As the protrusion cooled rather rapidly after heating, the temperature response of the internal thermocouple was expected to be sluggish and caused the temperature differences. 


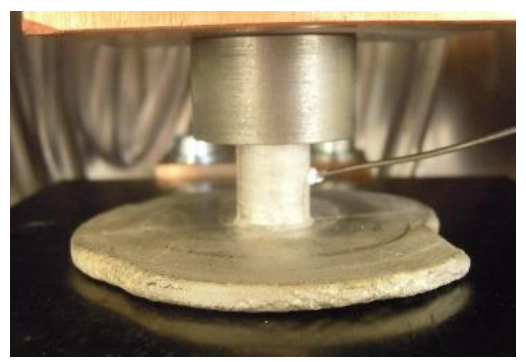

(a)

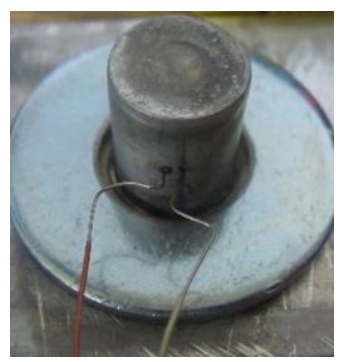

(b)

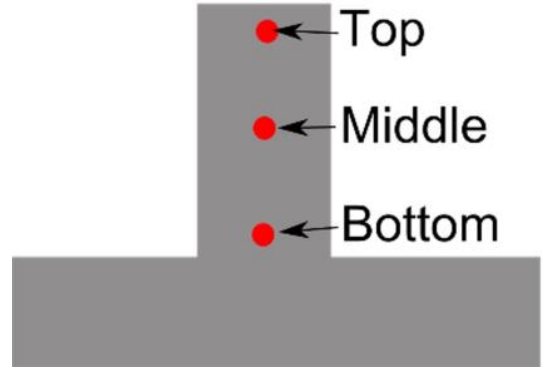

(c)

Fig. 5. (a) Thermocouple mounted inside a protrusion, (b) Thermocouple welded to the surface of a protrusion, and (c) locations of mounted thermocouples in the protrusion.

Table 2. A comparison of maximum internal and external temperatures measured on AM60 protrusion heated with the same CSTP of $81 \mathrm{kA}^{2}$-s. Internal and external temperatures were measured with a grounded, and shielded thermocouple and an external thermocouple welded to surface, respectively.

\begin{tabular}{cccc}
$\begin{array}{c}\text { Applied } \\
\text { Current }(\mathrm{kA})\end{array}$ & $\begin{array}{c}\text { Current Duration } \\
(\mathrm{s})\end{array}$ & $\begin{array}{c}\text { Max. Internal } \\
\text { Temperature }\left({ }^{\circ} \mathrm{C}\right)\end{array}$ & $\begin{array}{c}\text { Max. External } \\
\text { Temperature }\left({ }^{\circ} \mathrm{C}\right)\end{array}$ \\
\hline 0 to 9 & 1 & 232 & 270 \\
0 to 11 & 0.66 & 238 & 283 \\
0 to 13 & 0.49 & 242 & 291
\end{tabular}

\subsection{UPJ experimental test matrices}

\subsubsection{Experimental Test Matrix-1}

At least three identical experiments were conducted at the same process parameter settings to form UPJ joints. The tests were remarkably reliable and repeatable in terms of current-time and displacement-time history, but there was a varying outcome in terms of the quality of the joint. Therefore, the first test matrix was developed to assess the UPJ system capability and limits broadly and the resulting UPJ joint characteristics. This test matrix provided a semi-optimal UPJ profile for a $\mathrm{Mg}$ cast protrusion where three key process variables, (i) CSTP, (ii) maximum current, and (iii) compression rate, were evaluated. As a constant CSTP value tends to produce somewhat similar temperatures (see Table 2) and the three parameters are related to one another (maximum applied current, duration of application of current, and CSTP), only two of these were needed to be defined. Additionally, compression distance is another variable factor to create UPJ joints. 


\subsubsection{Experimental Test Matrix-2}

The second experimental test matrix was in the form of a Taguchi orthogonal array [26] to reduce the number of experiments and to assess the relative significance of each of the process variables. This was also constructed based on the three key variables in Table 2. In the Taguchi method, multiple parameters per experiment are changed, and fewer experiments are required to quantify the interaction between parameters. The first test matrix had three maximum currents, CSTPs, and compression rates. Each experiment was repeated at least three times, originally requiring 27 experimental setups and 81 samples. The Taguchi orthogonal array matrix, on the other hand, required only 9 experimental setups and 27 samples. A schematic of the Taguchi orthogonal array for this matrix is shown in Fig. 6(a). Each value is independent in that no two experiments can be directly compared to one another. To find a parameter trend, the mean of the three outputs at each compression rate value was obtained and compared (Fig. 6(b)). As not all input variables had a strong effect on the output value, noise in the data and experiment may be responsible for an inconclusive trend. Consequently, the signal-to-noise ratio, a term used to find the accuracy and precision of the value, was used. Standard deviation in the results was another quantity used to assess the output quantity. The Taguchi orthogonal array is optimal for output quantities such as the ultimate strength of the material, a value that is quantitative and not subjective (or operator dependent). However, for a more subjective quantity such as 'quality' of the UPJ joint as an output parameter (see ref [23] for ranking of quality), noise and some variability were expected in the data.

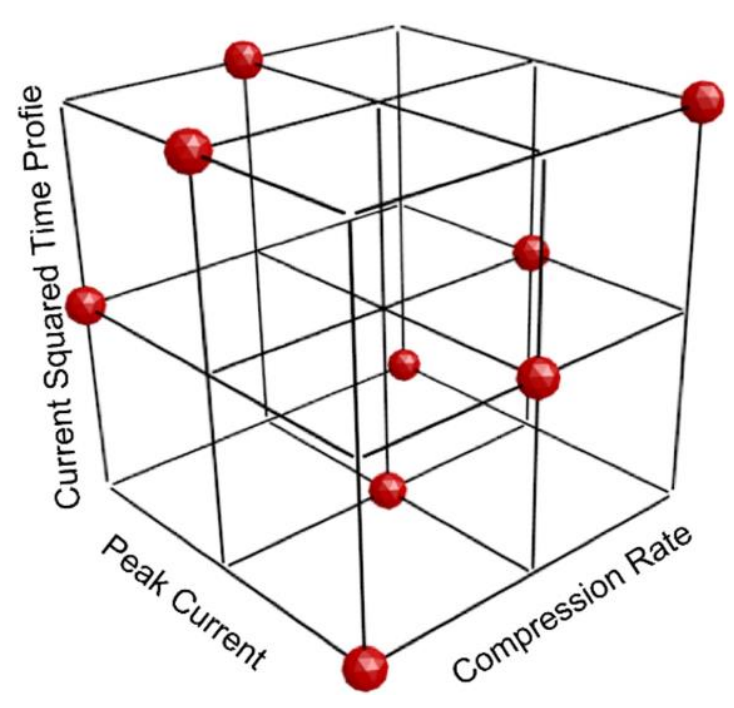

(a)

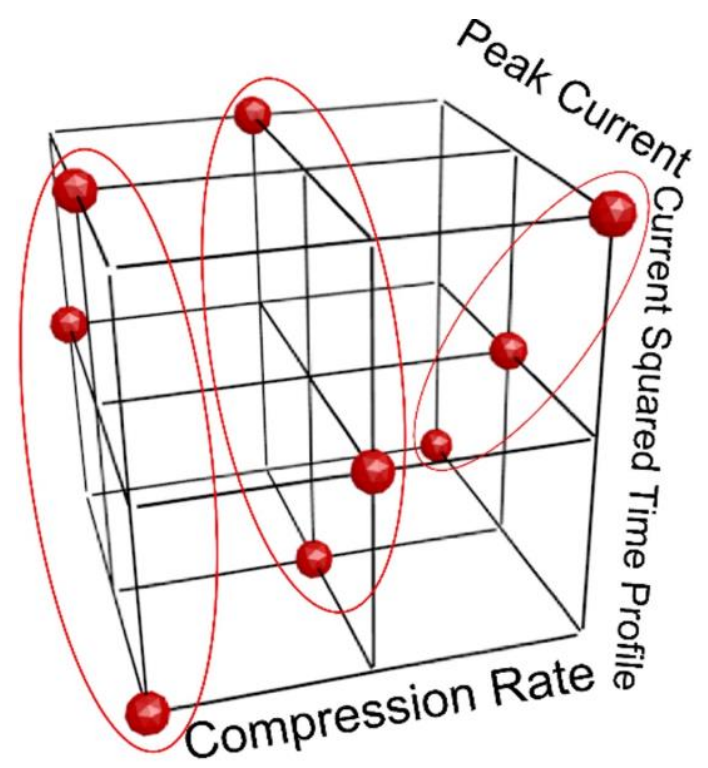

(b)

Fig. 6. (a) Taguchi orthogonal array for three process parameters, each with three potential values (low, medium, and high), and (b) test conditions marked with a red dot. Significance of 
the compression rate on the output quantity by utilizing the mean of the three sets of values (circled in red).

\subsection{Post-UPJ joint strength}

Lap shear UPJ joints were tested at room temperature in uniaxial tension to assess their performance in a tensile shear deformation mode. The test set-up utilized a servo-hydraulic MTS test frame. The samples were pulled at a constant displacement rate of $10 \mathrm{~mm} / \mathrm{min}$ to fracture while recording the load-displacement response of all test samples. 


\section{Results and Discussion}

\subsection{As-cast microstructure}

The typical microstructure of the cast AM60 alloy used in the present study is shown in Fig. 7(a). The microstructure exhibits grain size in the range of $20 \mu \mathrm{m}$ to $30 \mu \mathrm{m}$. It primarily consists of $\alpha_{\mathrm{Mg}}$ matrix (lighter background), $\mathrm{Mg}_{17} \mathrm{Al}_{12}$ intermetallic particles and the eutectic $\left(\alpha_{\mathrm{Mg}}+\mathrm{Mg}_{17} \mathrm{Al}_{12}\right)$ that are precipitated on the grain boundaries (etched preferentially). X-ray diffraction plot for the cast AM60 alloy is shown in Fig. 7(b), and the spectrum confirms the presence of $\mathrm{Mg}_{17} \mathrm{Al}_{12}$ intermetallic particles. Crystallites are assumed to be oriented randomly, which is typical of as-cast $\mathrm{Mg}$ alloys [27].

(a)
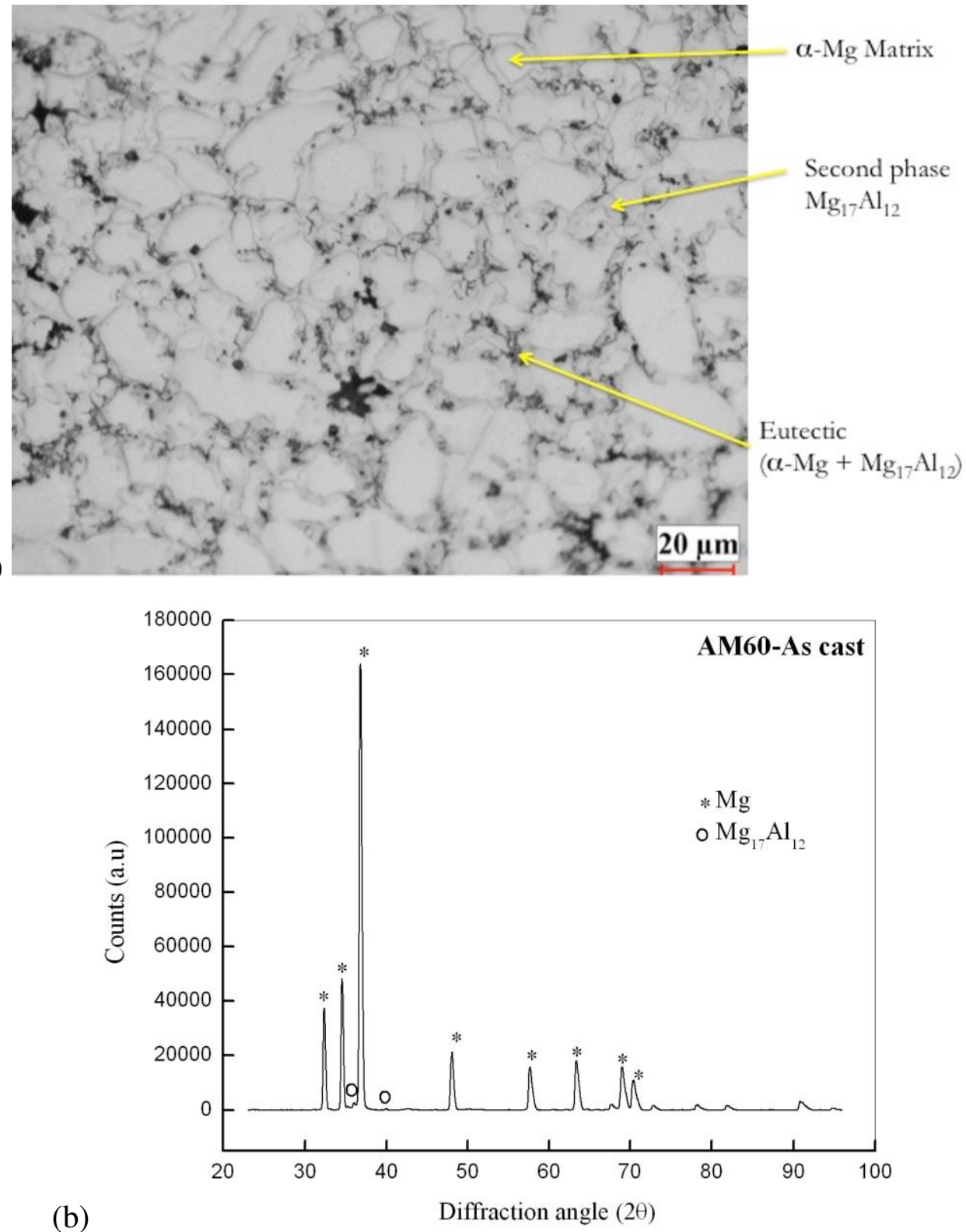

Fig. 7. (a) The optical microstructure and (b) the XRD pattern of the AM60 alloy in the as-cast condition. 


\subsection{UPJ trials for test repeatability (Load-displacement curves and protrusion's}

characteristics)

Ten repeated UPJ experiments were carried out on AM60 cast samples, each at a current of 0 to $11.5 \mathrm{kA}$ over 1.11 seconds and a compression rate of $21 \mathrm{~mm} / \mathrm{s}$ while keeping all other parameters as well as the test procedure identical. The objective here was to see if the punch load versus displacement was repeatable as a process 'signature'. Each of the protrusions was preloaded first, and then at 0.8 seconds, it was heated by supplying a current. At 2 seconds, the current was turned off, and the protrusion was compressed from an initial length of $14 \mathrm{~mm}$ to a length of $4 \mathrm{~mm}$ (thus providing a compression distance of $10 \mathrm{~mm}$ ). The protrusion was then held in position for another 0.2 seconds before the ram (actuator) was retracted to remove the specimen from the test system. The load versus time and actuator position versus profiles at various test stages are shown in Figs. 8(a) and 8(b), respectively. These tests were conducted in 'load control' during pre-loading and then switched to 'position control' for deforming the protrusion via compression. Consequently, in the predominantly elastic deformation during pre-loading, both load and position signals have minimal variability until the specimen heating occurs. Both load and position fluctuations occur due to frequent and unstable loss and reestablishment of contact between the electrode and the protrusion. However, during subsequent plastic deformation of the protrusion, the contact is permanently established, and the 'position control' is accurately maintained, as shown in Fig. 8(a). However, the peak load fluctuations likely occurred from sample to sample (see Fig. 8(b)) due to contact variations from either cast specimen top and bottom surface quality or perhaps material variability from the casting process. The results of test repeatability in terms of images of UPJ joints are shown in Fig. 8(c) from a set of 5 repeat tests. Four of the five UPJ samples exhibited largely crack-free deformation of the protrusion to create the joint head. 


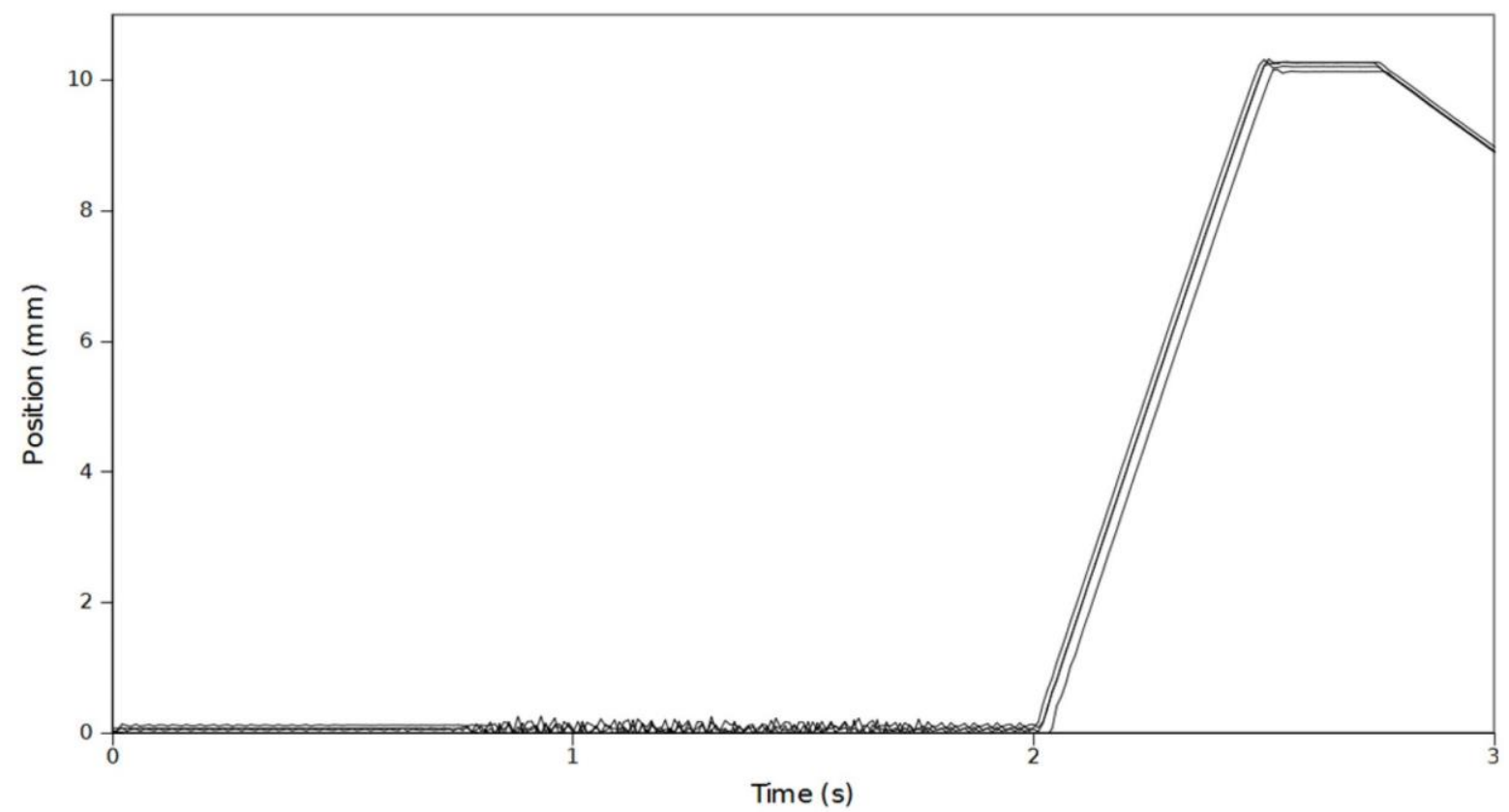

(a)

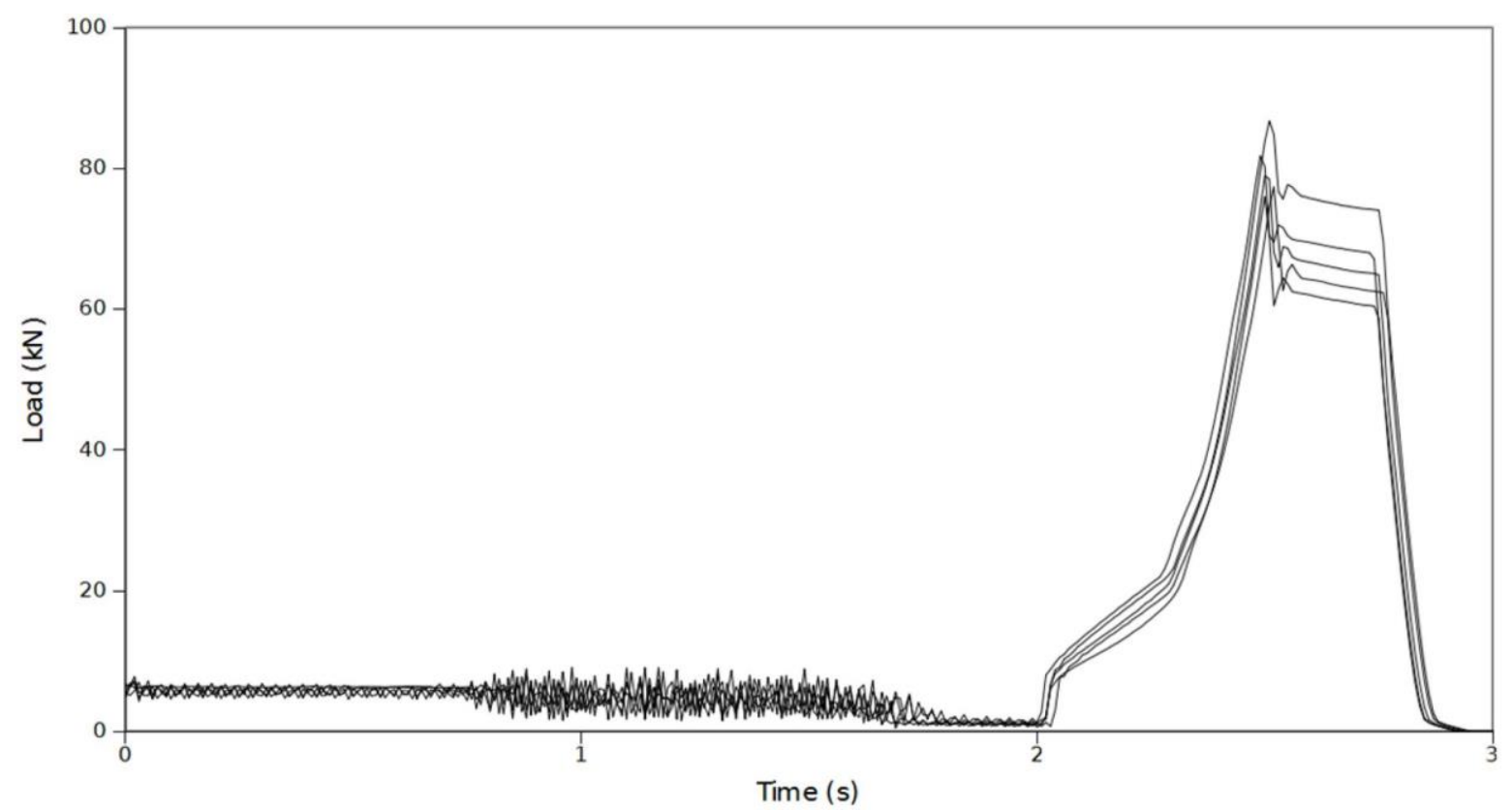

(b)
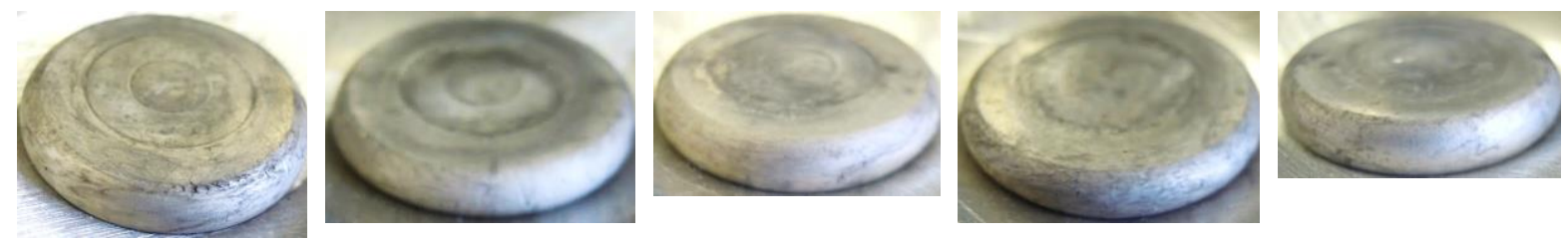

(c)

Fig. 7. (a) Position versus time curves and (b) Load versus time traces from repeated UPJ experiments at 0 to $11 \mathrm{kA}$ (peak current), $1.11 \mathrm{sec}$ (time), $21 \mathrm{~mm} / \mathrm{sec}$ (compression rate). (c) A comparison of the visual appearance of UPJ heads from 5 repeat tests. Four of the five tests did not indicate any cracks or fissures, while the fifth (leftmost) had small surface cracks on the top edge that did not penetrate into the protrusion. 


\subsection{Test Matrix-1 Results (Load-displacement curves and protrusion's characteristics)}

\subsubsection{Effect of heating rate}

Results from tests with a constant CSTP while changing the maximum current applied are shown in Fig. 8. Fig. 8(a) indicates that the change in the maximum current (9 kA, 10.25 kA, $11.5 \mathrm{kA})$ while keeping the CSTP constant (141 kA $\left.{ }^{2}-\mathrm{s}\right)$ had minimal effect on the load versus displacement curves (compression rate: $21 \mathrm{~mm} / \mathrm{sec}$ ). However, different maximum current values while maintaining a constant CSTP were found to cause a difference in the quality of the joint, as illustrated in Figs. 8(b-d). Increasing maximum current and decreasing the duration of heating to maintain a constant CSTP $\left(100 \mathrm{kA}^{2}-\mathrm{s}\right)$ resulted in a drastic increase in crack formation (compression rate: $31.5 \mathrm{~mm} / \mathrm{sec}$ ). The maximum current applied to a protrusion appeared to be linked and not independent of other parameters in the crack formation. Note that the increase in the applied current (decreasing the time to maintain constant CSTP) did not bring any significant change in the temperature within the protrusion. The other parameters include compression rate and compression distance. For example, at a CSTP of $141 \mathrm{kA}^{2}$-s, applying a very high maximum current (15 kA) produced good joints at a lower compression rate, i.e., $21 \mathrm{~mm} / \mathrm{sec}$ (see Fig. 8(e)).

From Figs. 8(b-d), it can be observed that the material tends to fracture with the increase in the applied current. The formability of the AM60 protrusion can be considered to consist of two separate parts: (i) intrinsic and (ii) state-of-stress $(\mathrm{SoS})$ related. The manipulation of SoS in the deformation zone is through design change which is not the focus of the present work. The first part, i.e., flow (deformation) behavior depends on the intrinsic nature of the AM60 alloy to respond under the imposed processed conditions, mainly temperature, strain rate, and strain (comes via applied current, compression rate, and compression distance in the UPJ context). In the authors' previous work [28], deformation processing map to correlate the constitutive response of AM60 alloy to the processing conditions in terms of the microstructural changes is reported. At lower temperatures $\left(<300{ }^{\circ} \mathrm{C}\right)$, the processing map exhibited regime of flow instability at all strain rates (from 0.1 to $5 \mathrm{~s}^{-1}$ ). In AM60 alloy, the eutectic phase is distributed on the grain boundaries of the matrix $\alpha$-phase but non-uniformly (Fig. 7(a)). Typically, eutectic phase region behaves in a brittle manner and causes early onset of damage and crack formation. At higher temperatures $\left(>400^{\circ} \mathrm{C}\right)$, the melting of the eutectic occurs, and it creates a two-phase semi-solid material that is unstable during deformation and is likely responsible for the failure of the protrusion. 


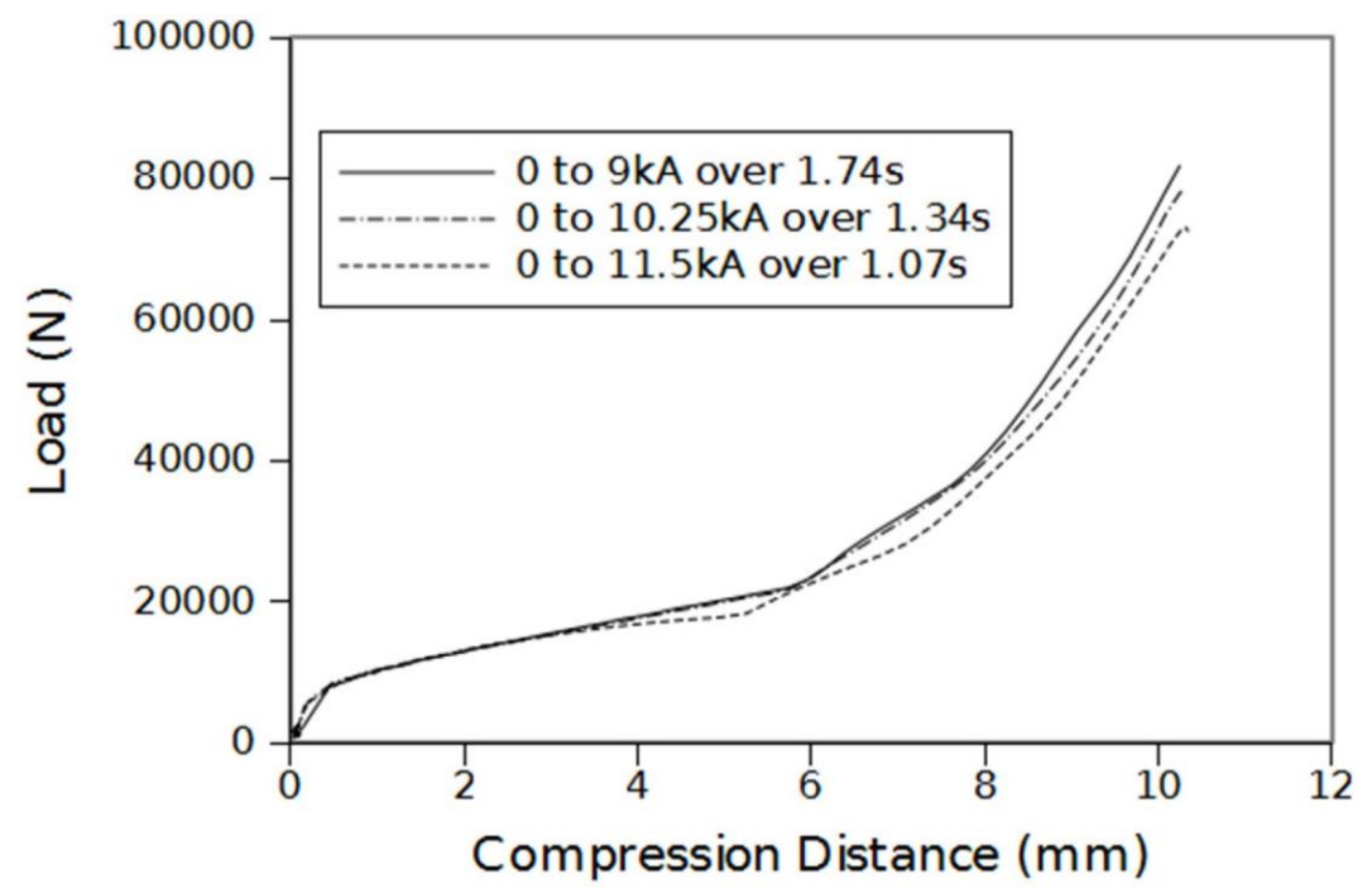

(a)

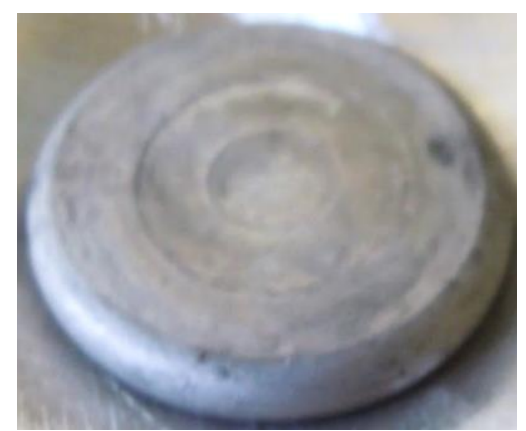

(b)

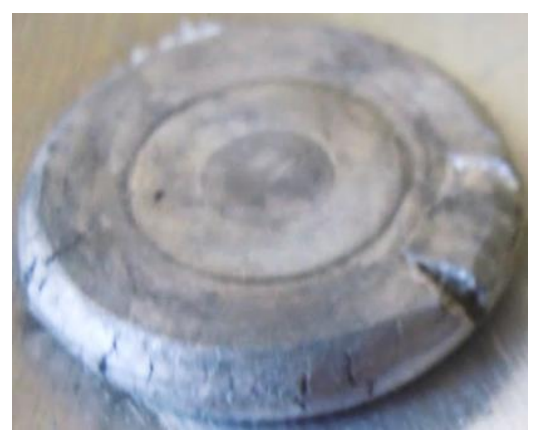

(c)

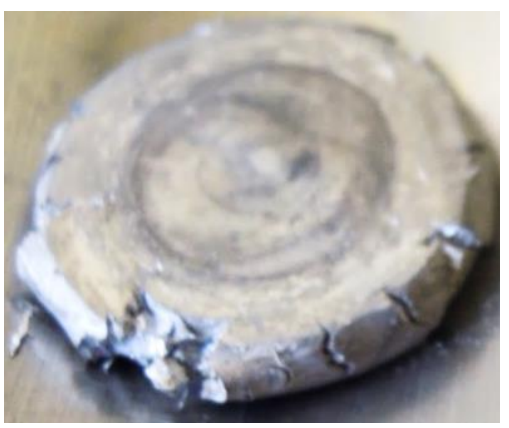

(d)

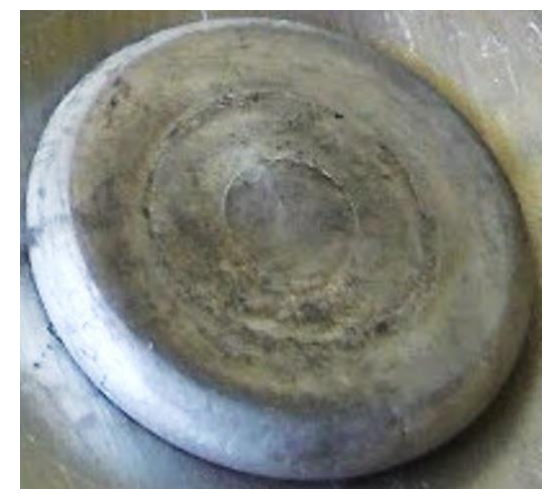

(e)

Fig. 8. (a) A comparison of Load versus time curves for AM60 protrusions compressed at a CSTP of $141 \mathrm{kA}^{2}$-s (compression rate: $21 \mathrm{~mm} / \mathrm{sec}$ ); A comparison of images of protrusion head compressed at a rate of $31.5 \mathrm{~mm} / \mathrm{s}$ and with the same CSTP of $100 \mathrm{kA}^{2}$-s and a maximum applied current of (b) $9 \mathrm{kA}$ (low), (c) $10.25 \mathrm{kA}$ (moderate), and (d) $11.5 \mathrm{kA}$ (high); (e) A defectfree UPJ head from AM60 protrusion formed with a maximum current of $15 \mathrm{kA}$ for 0.63 seconds and corresponding to a CSTP of $141 \mathrm{kA2}-\mathrm{s}$, at a compression rate of $21 \mathrm{~mm} / \mathrm{s}$ (i.e., very high maximum current, a high CSTP and a low compression rate). 


\subsubsection{Effect of CSTP value}

As mentioned in section 2.3, the increase in the magnitude of applied current and/or duration of applied current increases the CSTP value. Fig. 9(a) shows the effect of increasing CSTP during deformation while compression rate $(42 \mathrm{~mm} / \mathrm{sec})$ and maximum current $(11.5$ kA) applied were constant. The load tends to decrease with the increase in the CSTP value $\left(100,120\right.$, and $141 \mathrm{kA}^{2}$-s). Figs. 9(b-e) shows the effect of change in CSTP on cracking and failure of the protrusion. A set of four experiments were conducted where the CSTP was varied $\left(100,121,141\right.$, and $152 \mathrm{kA}^{2}$-s) while keeping the magnitude of the current (11.5 kA) and compression rate $(21 \mathrm{~mm} / \mathrm{sec})$ constant. CSTP had a strong effect on the crack formation where a lower CSTP produced surface cracks typically inclined at $45^{\circ}$ to the loading axis (Fig. 9(b)). When the CSTP was far higher, catastrophic failures were observed, as shown in Fig. 9(e). At optimal CSTP value (141 $\left.\mathrm{kA}^{2}-\mathrm{s}\right)$, the protrusion head tended to have a defect-free appearance with virtually no surface cracks, as shown in Fig. 9(d).

CSTP is found to have a direct effect on the protrusion temperature. A constant CSTP based on several different combinations of maximum applied current, and current duration resulted in approximately the same maximum temperature as measured by both embedded and surface mounted thermocouples in the mid-length location of the protrusion. Also, an increased CSTP value linearly increased the maximum temperature at the same mid-length location. Therefore, CSTP appears to provide a good measure of energy or heat input into the protrusion. As shown in Eq. (1), energy expression is a function of current squared, time, and resistance. As defined by Eq. (4), resistivity is a function of the cross-sectional area, the length, and the resistance in the system.

$$
\phi=\frac{R A}{L}
$$

$L$ is length, $A$ is the cross-sectional area, and $\phi$ is the resistivity of the specimen.

A third term, the increase in temperature of a bulk item, is as shown below:

$$
\Delta T=\frac{\text { Energy }}{C_{p} \rho L \pi r^{2}}
$$

$\mathrm{C}_{\mathrm{p}}$ is the specific heat in $\mathrm{kJ} / \mathrm{kg}-\mathrm{K}, \rho$ is the density in $\mathrm{kg} / \mathrm{m}^{3}, \mathrm{~L}$ is the length in $\mathrm{m}, \mathrm{r}$ is the radius in $\mathrm{m}$, and $\Delta \mathrm{T}$ is the change in temperature in ${ }^{\circ} \mathrm{C}$. Combining Eqs. (1), (4) and (5) yields the following equation. 


$$
\Delta T=\frac{\int_{0}^{t_{0}} I^{2} \frac{\phi L}{\pi r^{2}} d t}{C_{p} \rho L \pi r^{2}}
$$

where $\mathrm{t}_{0}$ is the duration of heating in seconds, $\phi$ is the resistivity of the alloy in ohm-m, and I is in coulombs per second. The equation is simplified as follows:

$$
\Delta T=\frac{\int_{0}^{t_{0}} I^{2} \phi d t}{C_{p} \rho\left(\pi r^{2}\right)^{2}}
$$

If one assumes that the parameters $\phi, \rho$ and $C_{p}$ vary with temperature such that the ratio $\left(\phi / C_{p} \rho\right)$ remains constant, Eq. (7) indicates the direct relationship of CSTP with the temperature of the protrusion. In this case, CSTP can serve as a helpful process variable for UPJ. However, the limitation of CSTP is that it does not account for heat loss to the surroundings.

A low CSTP was found to cause crack formation in the form of either slanted or zigzag cracks due to lack of dynamic recrystallization (Figs. 9(b) and (c)). Localization of deformation inside the microstructure due to lack of sufficient slip systems in $\mathrm{Mg}$ alloys at low temperature would cause shear bands to form inside the protrusion. The outer surface underwent high strains at a low temperature, leading to crack formation. The slanted cracks indicate that the protrusion was under hoop strain and failed in shear. A high CSTP caused the protrusion to completely shatter, as seen in Fig. 9(d). This may attribute to the heating beyond the eutectic temperature $\left(\sim 430^{\circ} \mathrm{C}\right)$ of the alloy, which causes for the eutectic phase on the grain boundaries to melt. The material inside the grains (primary $\mathrm{Mg}$ ) was solid or semi-solid, while the eutectic alloy in the grain boundaries $\left(\mathrm{Mg}_{17} \mathrm{Al}_{12}\right)$ would melt at around $438^{\circ} \mathrm{C}$ [29]. This would cause the material to fall apart on the microscopic grain boundaries instead of deforming as a macro alloy. An optimal CSTP (Fig. 9(c)) allowed dynamic recrystallization inside the protrusion. This prevented shear band formation and allowed the material to deform without failure if the strain rate (or compression rate) was also optimal. The processing map for AM60 alloy [28] indicates that the material exhibits good workability at higher than $>300^{\circ} \mathrm{C}$. 


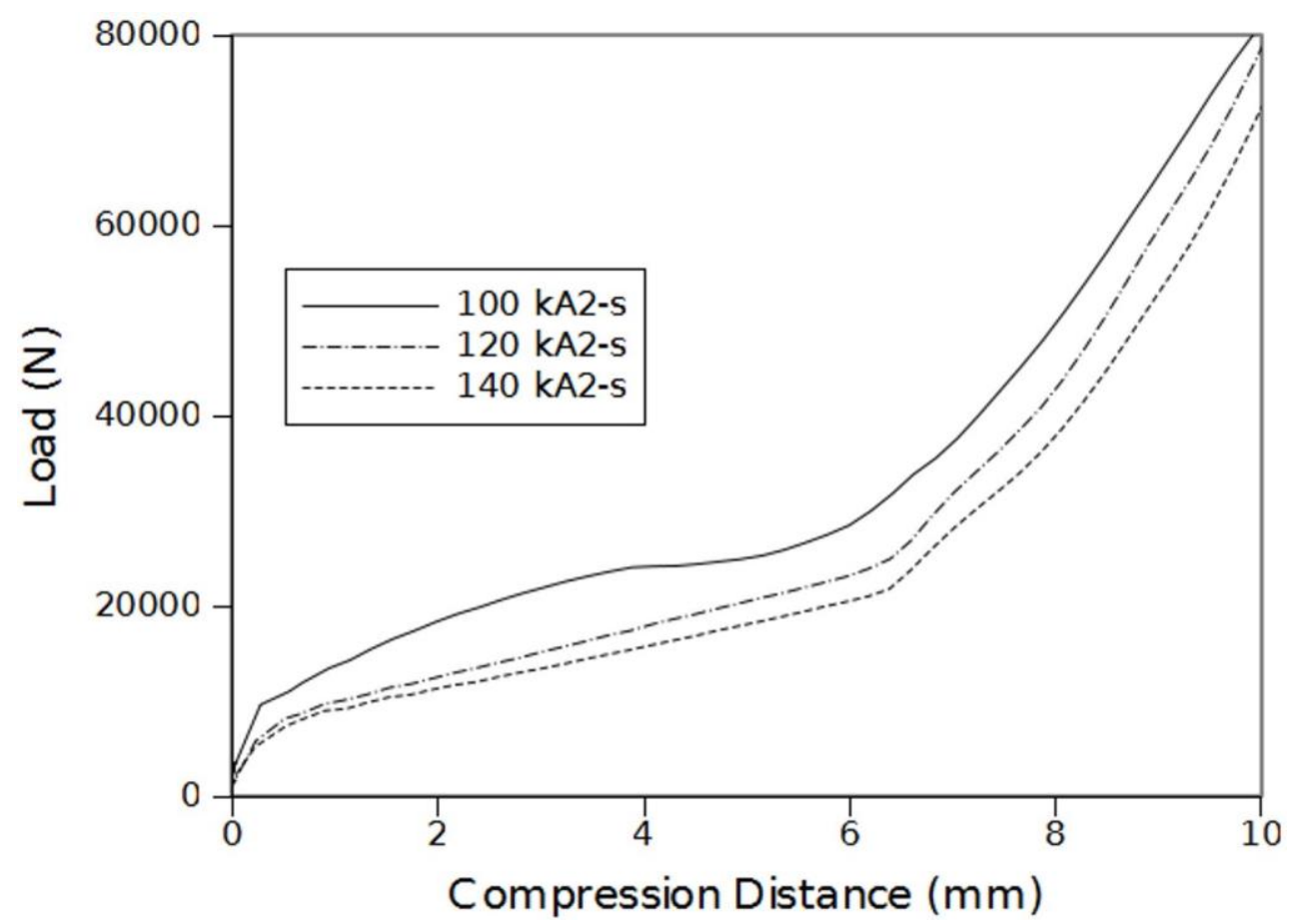

(a)

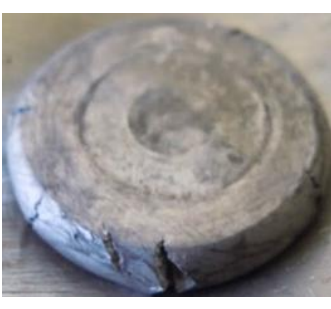

(b)

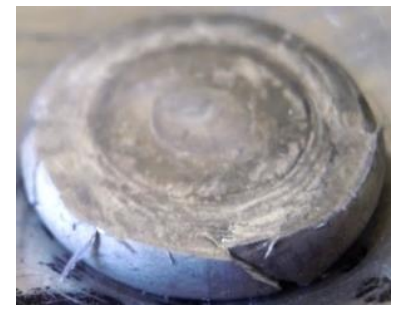

(c)

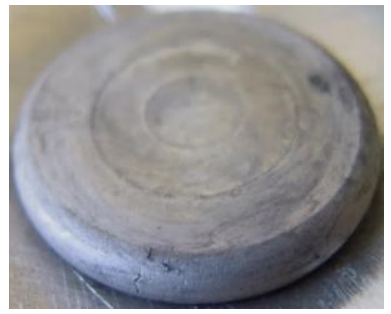

(d)

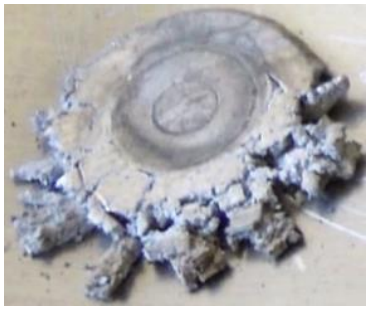

(e)

Fig. 9. (a) A comparison of changing the CSTP on the load versus time traces for AM60 alloy. The protrusion was compressed at a rate of $42 \mathrm{~mm} / \mathrm{s}$ over a distance of $10 \mathrm{~mm}$ with a maximum applied current of $11.5 \mathrm{kA}$; Effect of change in CSTP on fracture characteristics of AM60 protrusion compressed at a rate of $21.5 \mathrm{~mm} / \mathrm{s}$ and heated with a current profile from 0 to $11.5 \mathrm{kA}$ and with CSTP values of (b) $100 \mathrm{kA}^{2}-\mathrm{s}$, (c) $121 \mathrm{kA}^{2}$-s, (d) $141 \mathrm{kA}^{2}-\mathrm{s}$, and (e) $152 \mathrm{kA}^{2}-\mathrm{s}$.

\subsubsection{Effect of compression distance}

An increasing compression distance (keeping other parameters constant) did not affect the load versus displacement curve of the compression of AM60, as shown in Fig. 10(a). All curves fell on top of one another. This test data could also be considered as a measure of good test-to-test repeatability. Increasing compression distance directly affected the initiation, size, and the number of cracks in AM60 protrusion, as shown in Figs. 10(b-d). Compression distance was a crucial factor in crack formation since increasing compression directly implies increasing applied strain to the specimen. However, it should be noted that the protrusion head may typically have a fixed final diameter requirement in industrial practice, and this would be 
dependent on a fixed value of compression distance. Therefore, compression distance was not considered as a useful process variable for the Taguchi orthogonal array matrix (these results are presented later).

AM60 protrusions were heated with 0 to $11.5 \mathrm{kA}$ over 1.07 seconds (a CSTP of $141 \mathrm{kA}^{2}$ s) and compressed at a rate of $21 \mathrm{~mm} / \mathrm{s}$ to distances of $5.5 \mathrm{~mm}, 7.5 \mathrm{~mm}$ and $9.5 \mathrm{~mm}$. This profile was found to produce optimal results. The samples were cut, mounted, polished, and the microstructures were observed. The microstructures exhibited recrystallization in $5.5 \mathrm{~mm}$ and $7.5 \mathrm{~mm}$ compression, as shown in Figs. 10(e) and 10(f). Fig. 10(g) shows the $9.5 \mathrm{~mm}$ compression sample had some recrystallization, but shear bands and grain deformations indicate that the recrystallization was incomplete. This is believed to be due to the rapid increase in strain rate and the decrease in temperature of the protrusion during the last millimetre of compression as the Al sheet's thickness accounts for nearly half of the protrusion height. During the last two millimetres of compression, this sheet metal increased the strain rate significantly. The temperature of the protrusion decreases due to the conduction of heat to the electrode and the plate portion of the casting, reducing the formability of the protrusion. 


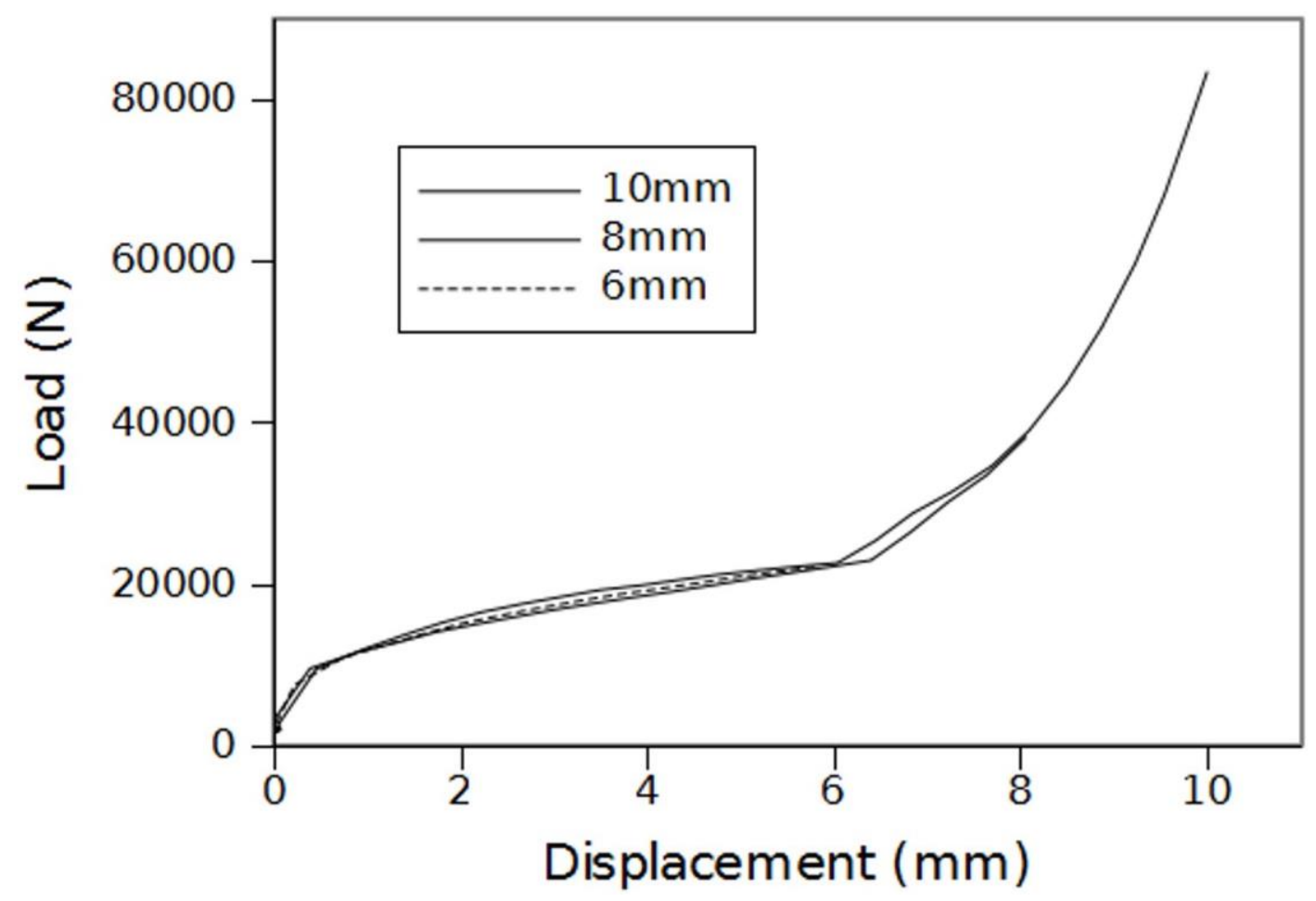

(a)

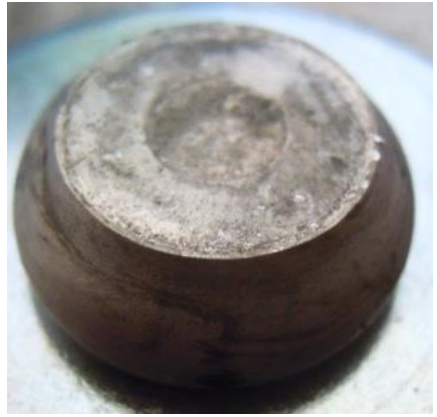

(b)

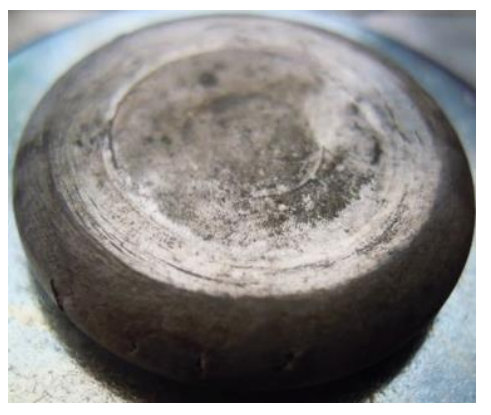

(c)

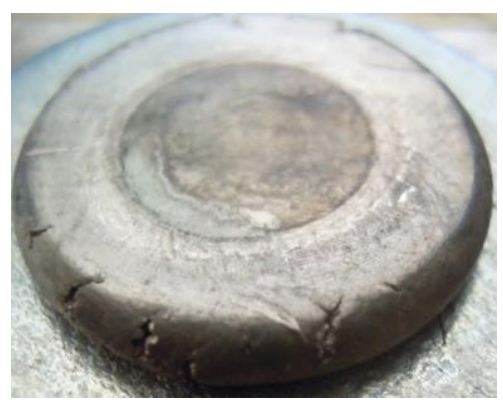

(d)

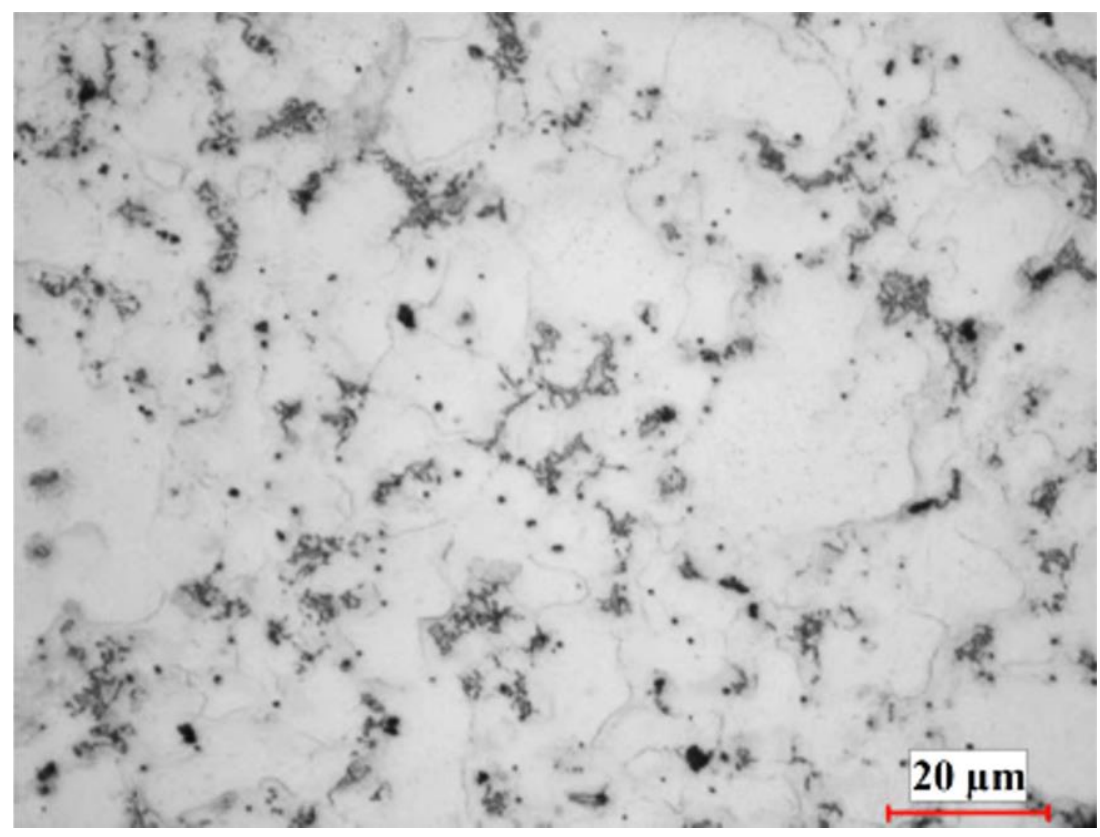

(e) 


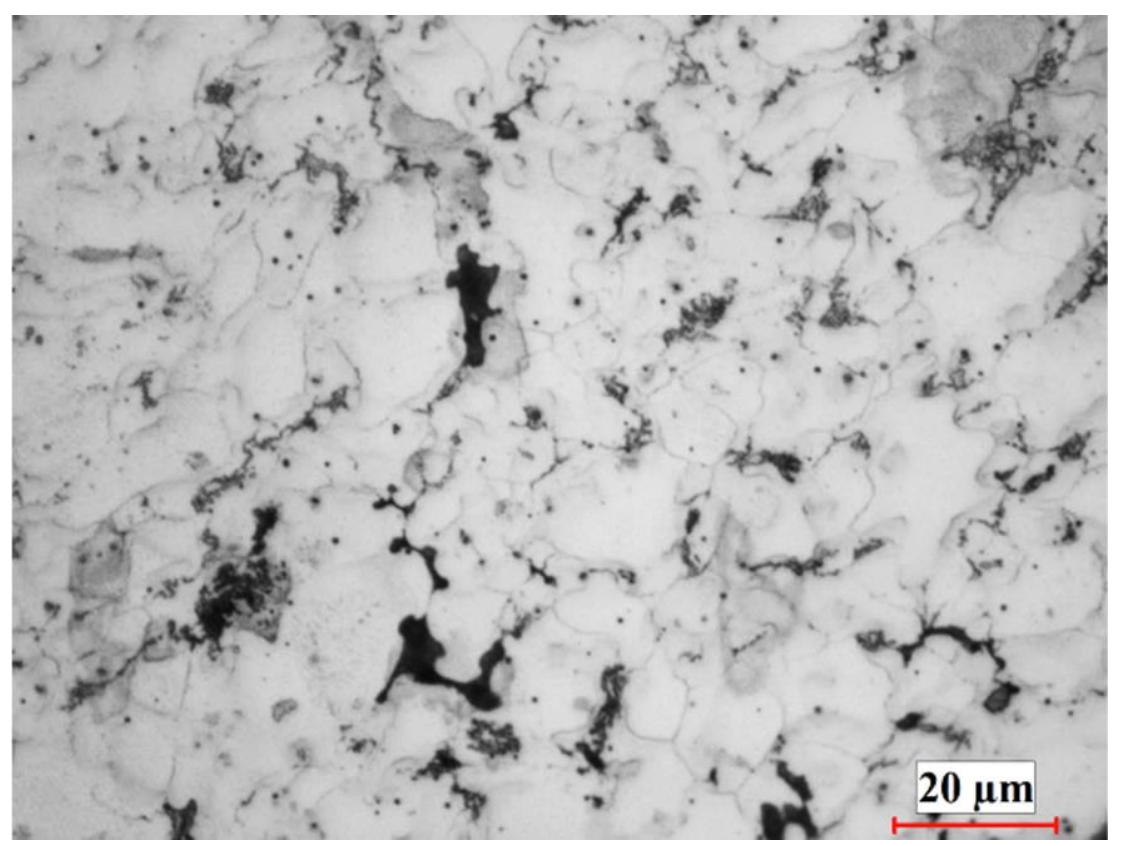

(f)

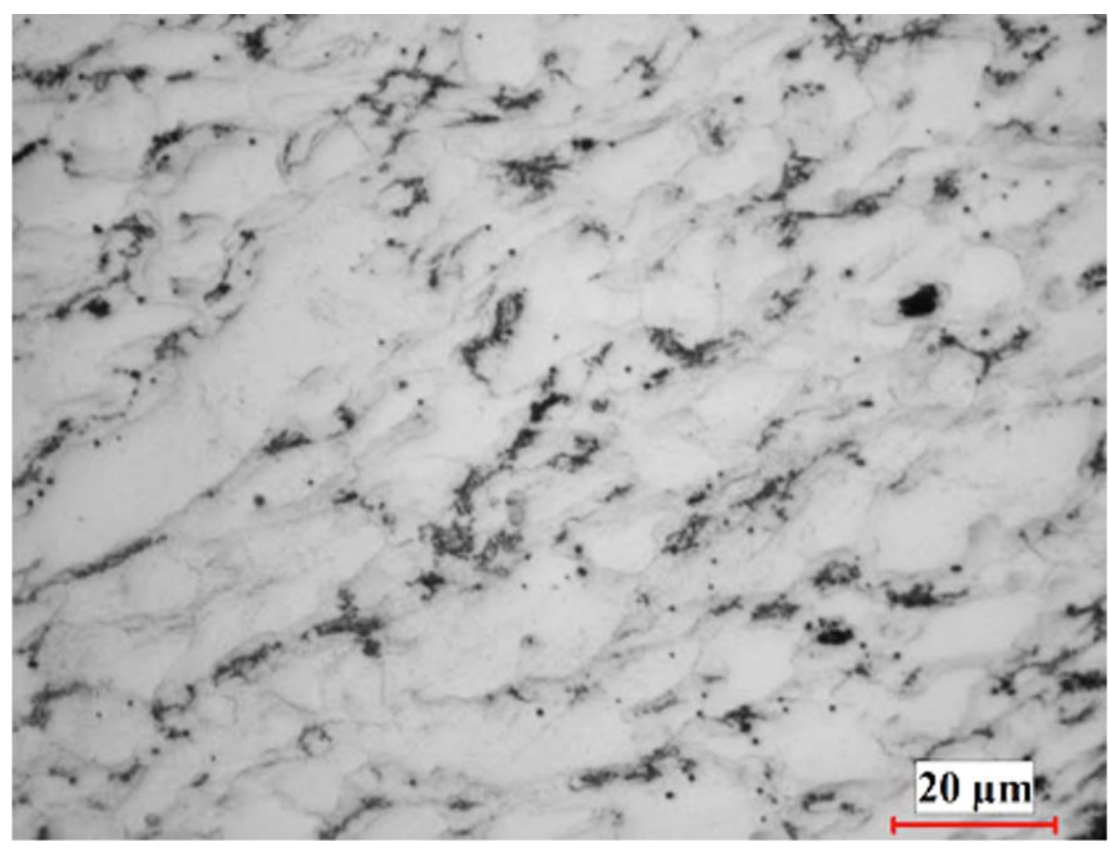

(g)

Fig. 10. (a) A comparison of load versus displacement of protrusions heated with 0 to $11 \mathrm{kA}$ over 1 second, a CSTP of $121 \mathrm{kA}^{2}$-s and compressed at a rate of $42 \mathrm{~mm} / \mathrm{s}$ for three different compression distances, and comparison of compression distance on the presence of crack size and density for distances, (b) $6 \mathrm{~mm}$, (c) $8 \mathrm{~mm}$, and (d) $10 \mathrm{~mm}$. Optical micrographs (50x) of the sliced and mounted AM60 protrusion samples compressed with 0 to $11.5 \mathrm{kA}$ over 1.07 seconds (a CSTP of $141 \mathrm{kA}^{2}$-s) at a rate of $21 \mathrm{~mm} / \mathrm{s}$ for compression distances of (e) $5.5 \mathrm{~mm}$, (f) $7.5 \mathrm{~mm}$, and (g) $9.5 \mathrm{~mm}$. 


\subsubsection{Effect of compression rate}

The effect of compression rate on load-displacement traces for AM60 protrusion is shown in Fig. 11(a) for three different values of compression rates. The load values remain close together for the three compression rates until the last stages of deformation, when the peak load increased with an increase in the compression rate. The increase in load with compression rate is consistent with the positive strain rate sensitivity of cast AM60 at higher temperatures [28]. Compression rate was a key parameter affecting the quality of the protrusion head for AM60 alloy. Both faster and slower compression rates led to crack formation on the periphery. At the slower rate of $15 \mathrm{~mm} / \mathrm{s}$ (Fig. 11(b)), there was increased heat loss to the surrounding, which reduced the outer surface temperature of the protrusion and thus reduced its ductility and likely increased its propensity for fracture. However, for intermediate compression rates of $21 \mathrm{~mm} / \mathrm{sec}$ and $31.5 \mathrm{~mm} / \mathrm{s}$, mostly defect-free protrusion heads were obtained, as shown in Figs. 11(c) and 11(d). At higher compression rates, as shown in Fig. 11(e), the material exhibited plastic instability likely due to increasing evidence of adiabatic shear banding in the microstructure (see Figs. 11(f) and (g)). 


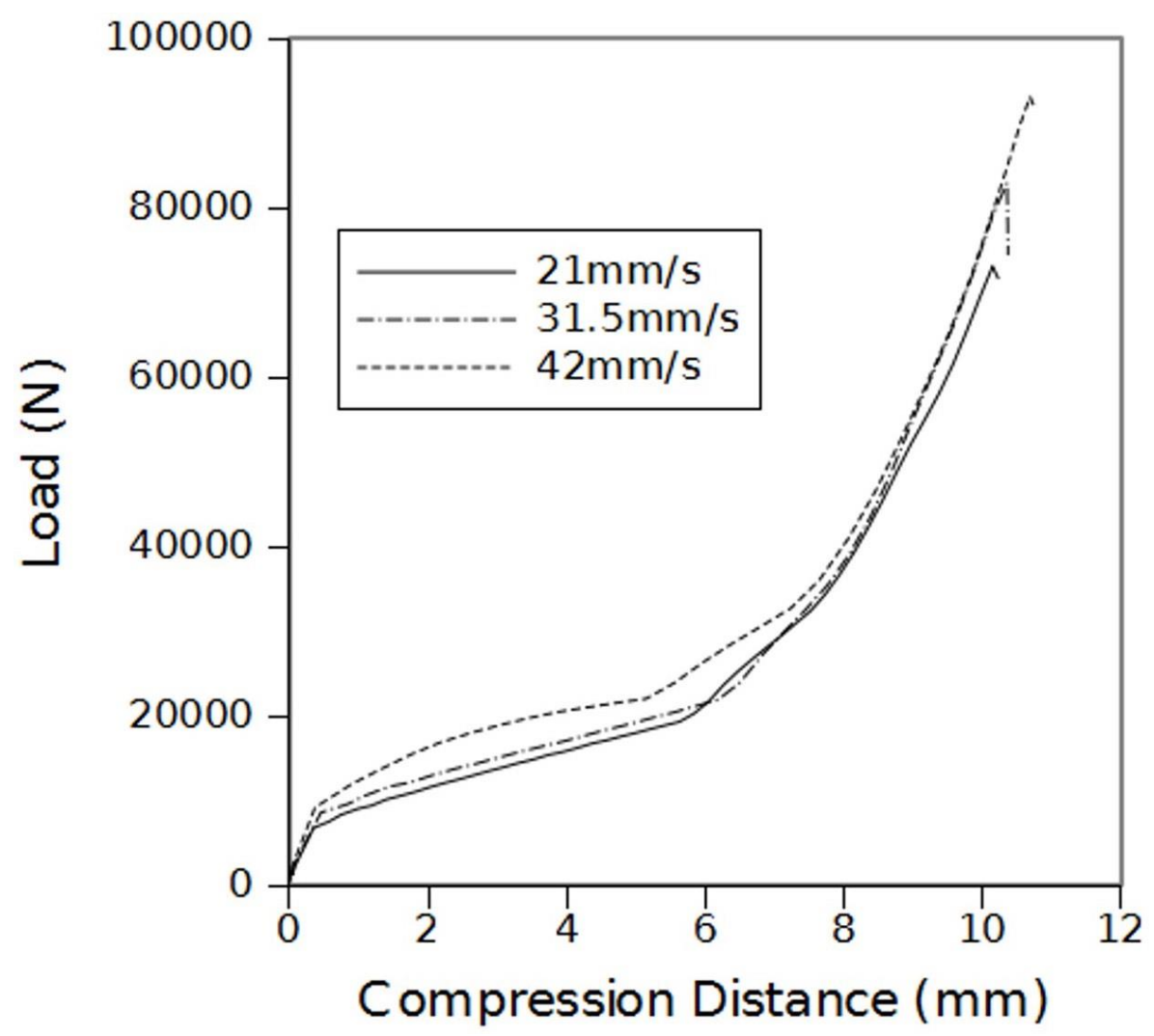

(a)

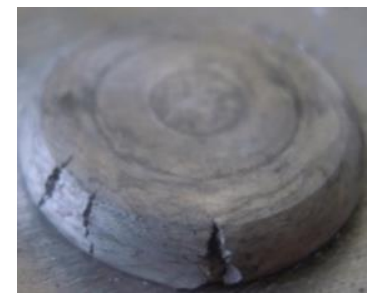

(b)

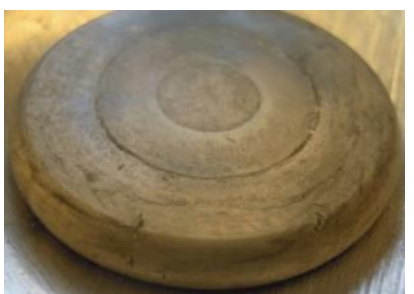

(c)

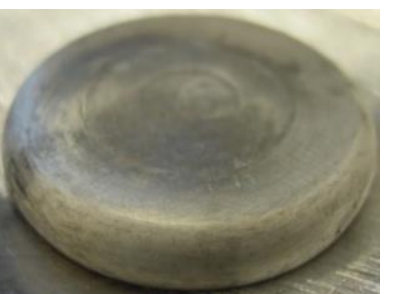

(d)

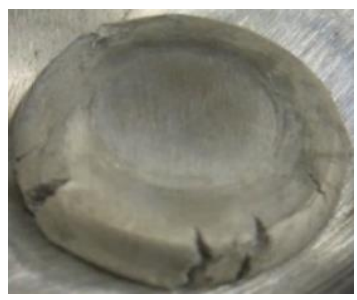

(e)

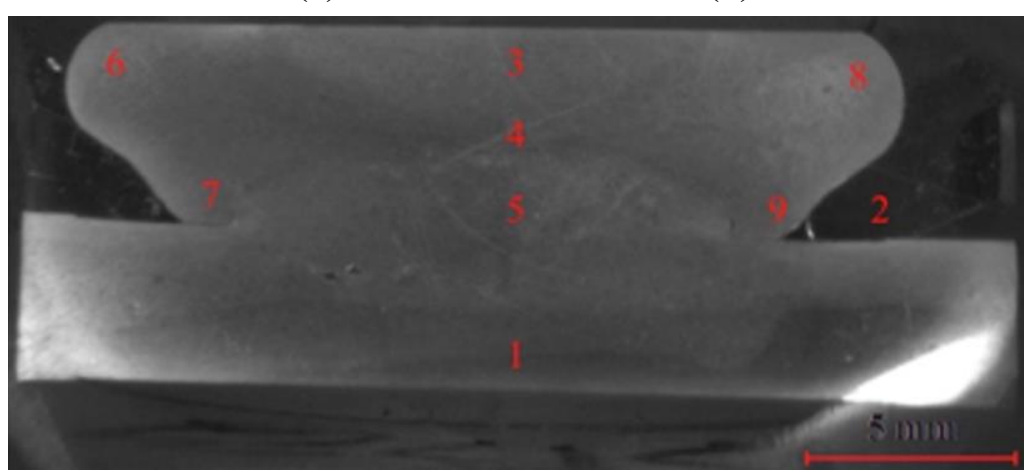

(f) 


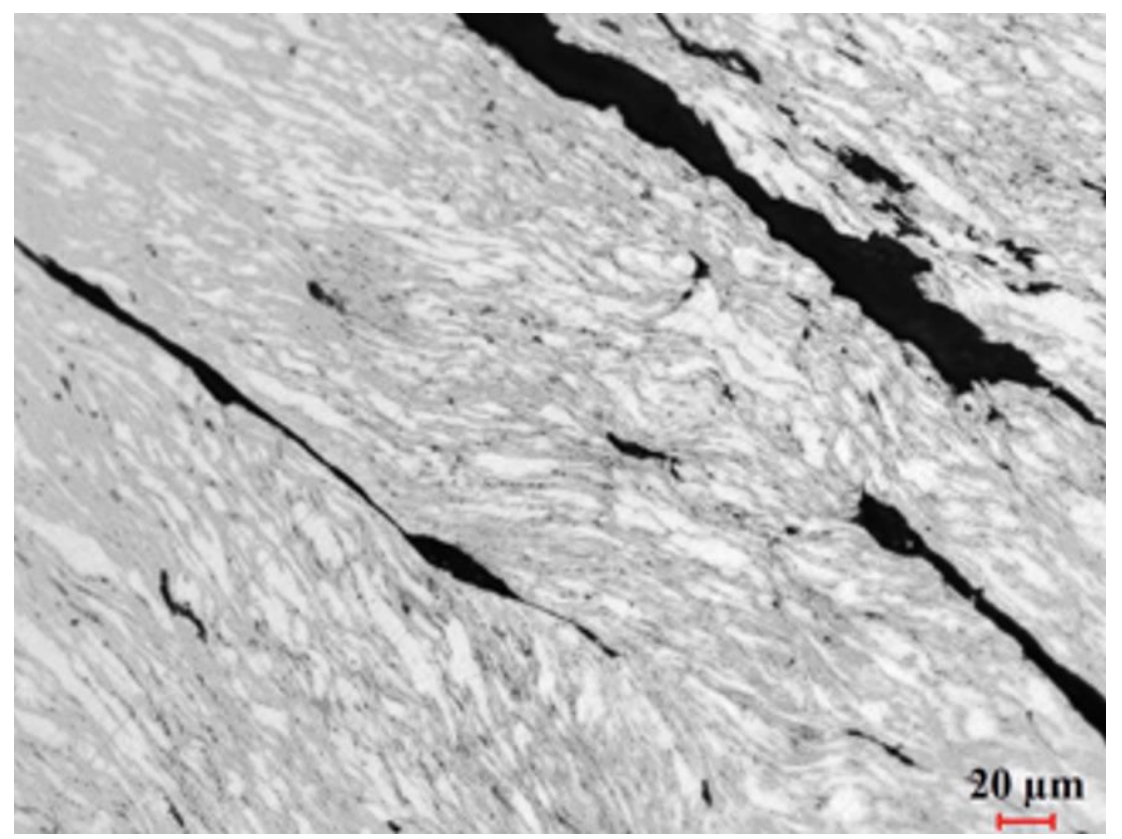

$(\mathrm{g})$

Fig. 11. (a) Load versus displacement traces for three different compression rates when the protrusions were heated with a CSTP of $141 \mathrm{kA}^{2}$-s and a maximum current of $11.5 \mathrm{kA}$. A comparison of UPJ joints of AM60 heated with 0 to $11.5 \mathrm{kA}$ over 1.08 seconds (a CSTP of 141 $\mathrm{kA}^{2}$-s) and compressed at a rate of (b) $15 \mathrm{~mm} / \mathrm{s}$, (c) $21 \mathrm{~mm} / \mathrm{s}$, (d) $31.5 \mathrm{~mm} / \mathrm{s}$, and (e) $42 \mathrm{~mm} / \mathrm{s}$. The optical micrograph of the joint compressed at $42 \mathrm{~mm} / \mathrm{s}$ in (g) shows micro-cracking, which is from location 8 (top right) in macro-view (f).

\subsection{Test Matrix-2 Results (Taguchi orthogonal array)}

Taguchi method [26] is well recognized for establishing the significance of specific process variables on the process outcome, which in the present work was in terms of a quality index (a scale from 1 to 10) of the UPJ part by visual inspection (see Ref [23]). A Taguchi orthogonal experimental array was created with UPJ process variables: compression rate (CR), maximum current (MC), and CSTP value, where each of the variables was assigned three different values (low, medium and high) based on the UPJ process limits of the equipment designed at McMaster University. The $\mathrm{R}^{2}$ value as a measure of scattering in the prediction data was also calculated.

The results of Taguchi analysis for AM60 are shown in the form of (i) mean of means, (ii) mean of standard deviation, and (iii) mean of signal/noise (S/N) ratio in Figs. 12(a-c), respectively. A higher mean of means, a lower mean of standard deviation, and a lower mean of $\mathrm{S} / \mathrm{N}$ ratio are considered the most desirable for an 'optimum' combination of the process variables. From the Taguchi analysis, the optimal process variables consisted of a maximum 
current of $11.5 \mathrm{kA}$, a CSTP value of $141 \mathrm{kA}^{2}-\mathrm{s}$, and a compression rate of $42 \mathrm{~mm} / \mathrm{s}$. The $\mathrm{R}^{2}$ value of the accuracy of prediction was $71 \%$. Based on the above 'optimum' values, a set of three repeat experiments were performed, and the results are shown in Figs. 12(d-f). The results show that not all repeat tests based on Taguchi analysis yielded a good quality protrusion head.

The Taguchi Orthogonal Array was used to optimize for a crack-free protrusion. However, it did not produce an optimal joint. The optimal joints were found through further experiments and analysis of the results. The Taguchi Orthogonal Array is suited for situations where the set of process variables relates to quantifiable and measurable output parameters such as yield strength and ultimate strength of a material. Higher and lower strength can be achieved, and the parameters in the experiment may have linear, exponential, or other trends with respect to strength. For the UPJ process, as the joint quality was assigned a value from a chart and the values had an absolute maximum of 10 , the equation relating process variables to UPJ joint quality was unable to find a set trend, let alone relationships amongst parameters. Such interrelationships were seen only by empirical observations. For example, a combination of low maximum current and a high compression rate produced a good UPJ joint in AM60, while a high maximum current and low compression rates could produce an even better UPJ joint. Similarly, a combination of low maximum current and low compression rate, as well as a combination of high maximum current and high compression rate, produced failures of the protrusion head in the UPJ joint. A new means of finding a quantitative value for the crack is needed for the Taguchi method to become suitable for optimizing the UPJ process. 


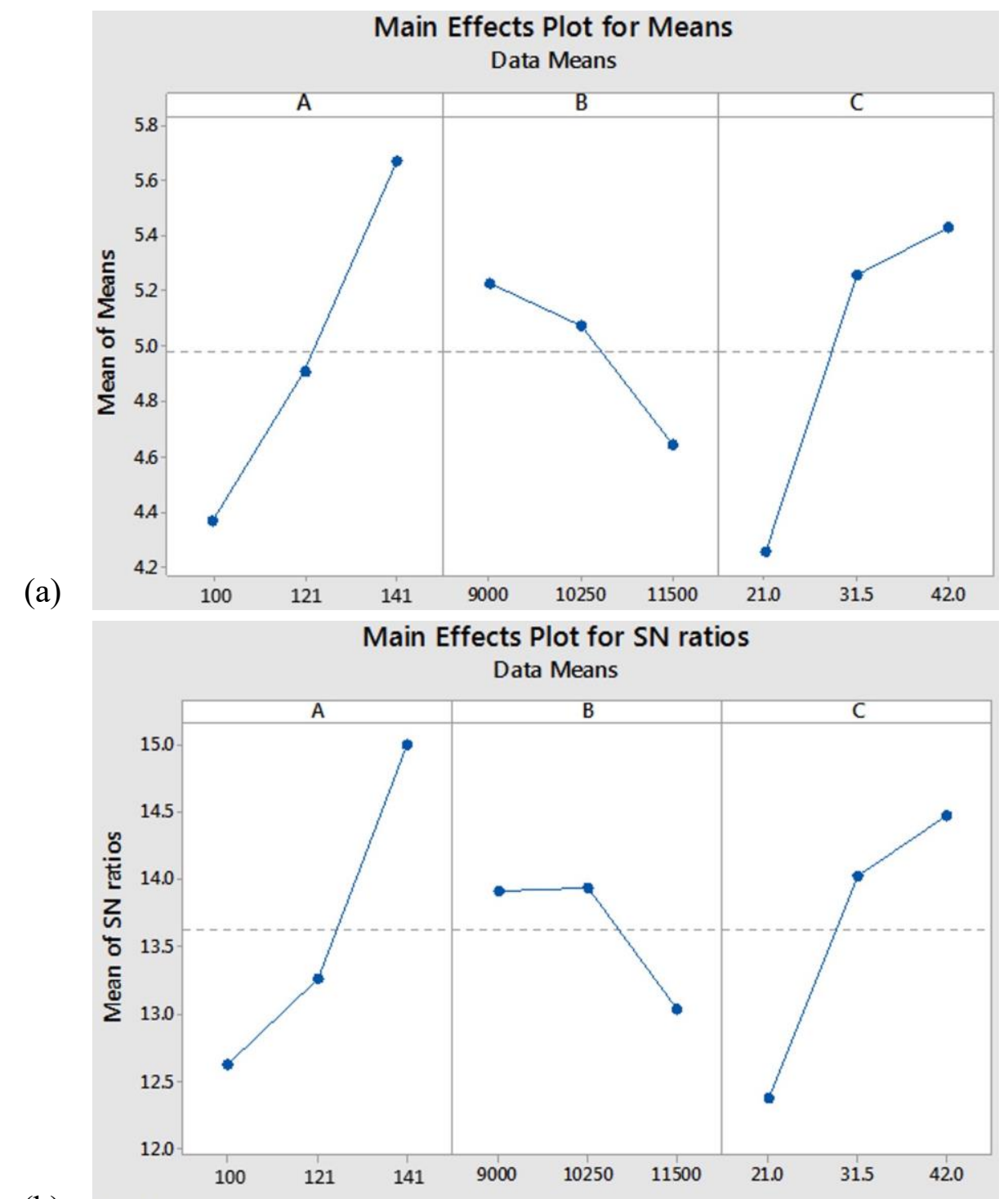

(b) Signal-to-noise: Larger is better

\section{Main Effects Plot for StDevs}

Data Means

(c)

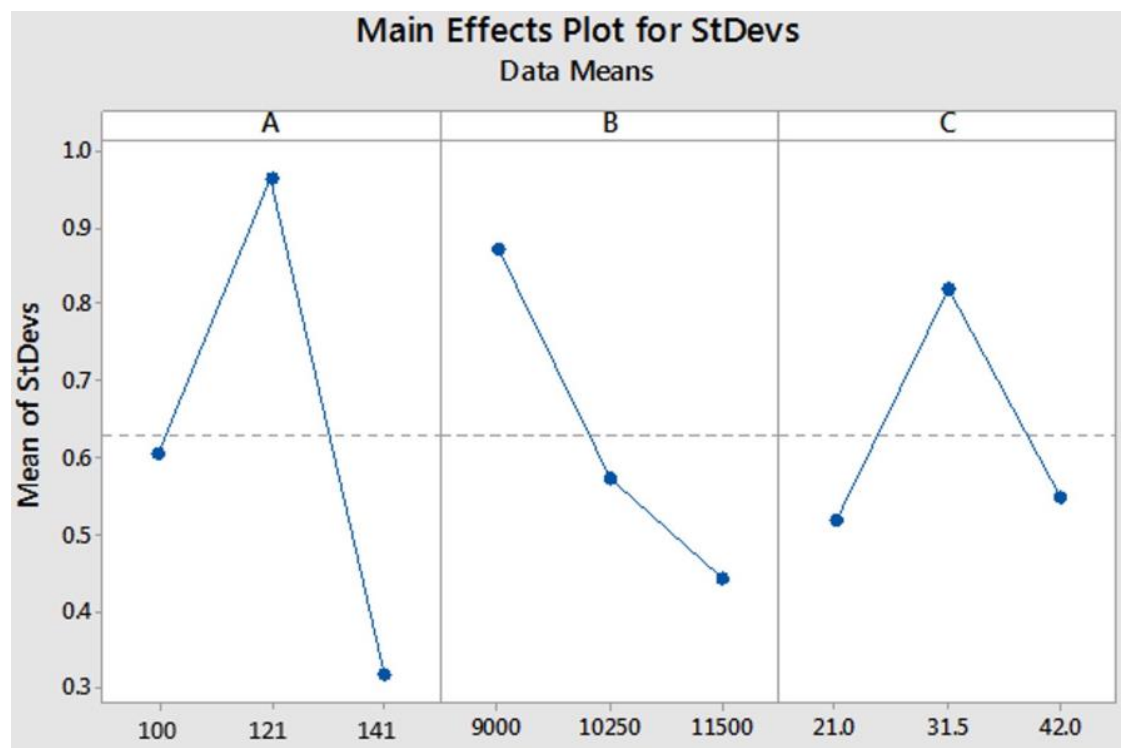




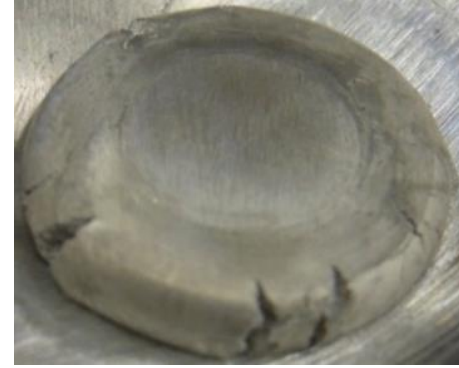

(d)

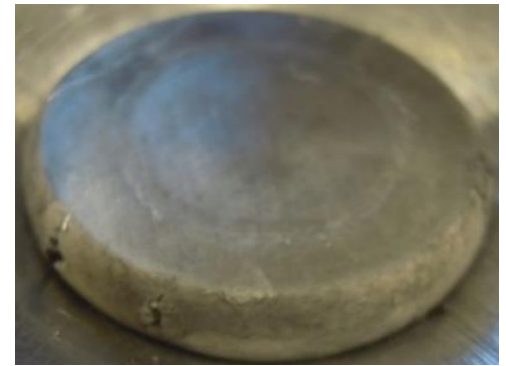

(e)

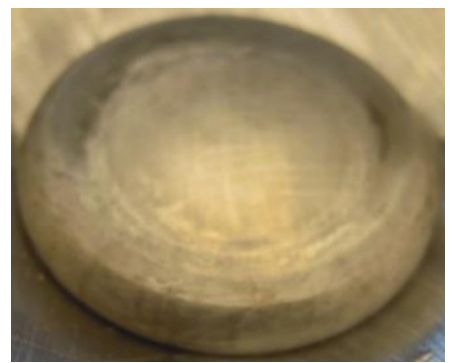

(f)

Fig. 12. (a-c) Results of Taguchi analysis for UPJ process optimization for part quality of AM60 alloy with the columns of CSTP, maximum current, and compression rate. (d-f) shows three repeat tests for AM60 alloy based on Taguchi optimal process variables. The protrusions were compressed at $42 \mathrm{~mm} / \mathrm{s}$, a maximum current of $11.5 \mathrm{kA}$, and a CSTP of $141 \mathrm{kA}^{2}$-s.

\subsection{Further process optimization}

Due to the limited success of the Taguchi orthogonal array experimental matrix, more ad-hoc post-UPJ parametric optimization experiments were performed. Trends were noted during these additional experiments that resulted in visually good quality joints. In addition, further changes to the CSTP value, heating rate, and compression rate were performed. For AM60, a parameter using a CSTP of $141 \mathrm{kA}^{2}$-s, a maximum current of $11.5 \mathrm{kA}$, and compression at a rate of $31.5 \mathrm{~mm} / \mathrm{s}$ produced perfect and nearly perfect results in repeat experiments. In contrast, the optimal result from Taguchi orthogonal array had the same heating profile but a somewhat different compression rate of $42 \mathrm{~mm} / \mathrm{s}$, producing a sub-optimal outcome.

A set of experiments with a heating profile of 0 to $11.5 \mathrm{kA}$ over 1.08 seconds, a CSTP of $141 \mathrm{kA}^{2}$-s with varying compression rates was performed. It was found that $21 \mathrm{~mm} / \mathrm{s}$ produced optimal results, and Figs. 13(a-c) shows the view of UPJ joints. A slower compression of 15 $\mathrm{mm} / \mathrm{s}$ had cracking indicating sub-optimal temperatures during compression despite being heated with the same CSTP (not shown for brevity). This may be attributed to the heat loss from the protrusion to the surroundings with compressions slower than $21 \mathrm{~mm} / \mathrm{s}$. Specimens obtained under optimal conditions ( 0 to $11.5 \mathrm{kA}$ over 1.08 seconds and compressed at $21 \mathrm{~mm} / \mathrm{s}$ with compression distances of $5.5 \mathrm{~mm}, 7.5 \mathrm{~mm}$ and $9.5 \mathrm{~mm}$ ) were cut axially through the middle of the protrusion and mounted, as shown in Figs. 13(d-f). A large porosity was present in the protrusion compressed to $5.5 \mathrm{~mm}$ (Fig. 13(a)).

The microstructures of specimens compressed to distances of $5.5 \mathrm{~mm}, 7.5 \mathrm{~mm}$ and 9.5 $\mathrm{mm}$, respectively, were presented in Figs. 10(e-g). The microstructures exhibited fine recrystallized grains with curved grain boundaries indicating that dynamic recrystallization 
(DRX) occurred when the protrusion was heated and compressed at these conditions. From their smaller grain size of about $10 \mu \mathrm{m}$ relative to the initial as-cast grain size of $30-40 \mu \mathrm{m}$, dynamically recrystallized grains were observed. From Fig. 10(g), it can be seen that the grain growth or the recrystallization during the final $2 \mathrm{~mm}$ of compression is somewhat less extent compared to compression from 0 to $7.5 \mathrm{~mm}$. This may be attributed to the increase of equivalent strain rate when the specimen is compressed at a distance of $9.5 \mathrm{~mm}$. Due to the less time available, the growth of newly formed nuclei is incomplete, although nucleation and the formation of new nuclei have occurred.

AM60 was found to yield optimal UPJ joint quality at a lower compression rate (21 $\mathrm{mm} / \mathrm{s}$ ) and a high CSTP of $141 \mathrm{kA}^{2}$-s. The maximum current was found to have a relatively small effect on the result, as seen in Fig. 13. From extrapolation of thermocouple data, the centre of protrusion at the mid-length location had a temperature near $400^{\circ} \mathrm{C}$. According to the Taguchi array, the optimal compression rate was $42 \mathrm{~mm} / \mathrm{s}$, while repeated experiments at this compression rate yielded poor and inconsistent results. The skin temperature of the protrusion appears to be critical as to how the protrusion deforms towards the later stages of the joint. As the temperature of the skin reduces, it becomes less ductile and prone to early fracture.

The optimal compression rate of $21 \mathrm{~mm} / \mathrm{s}$ was also tested at higher heating rates of 0 to 15 kA over 0.62 seconds, which occasionally produced good results. The material would melt just under the top surface in some repeat experiments, showing liquid metal formation. This melting did not affect the surface quality of the barrelled cylindrical (see Fig. 14).

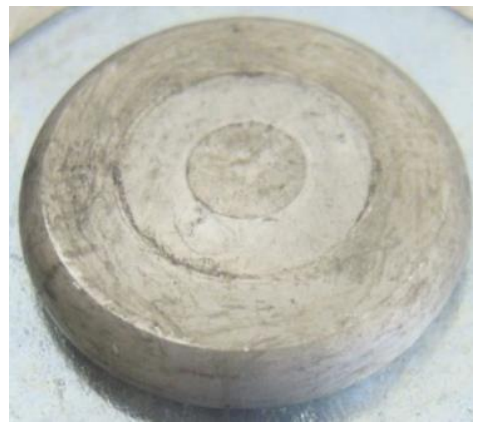

(a)

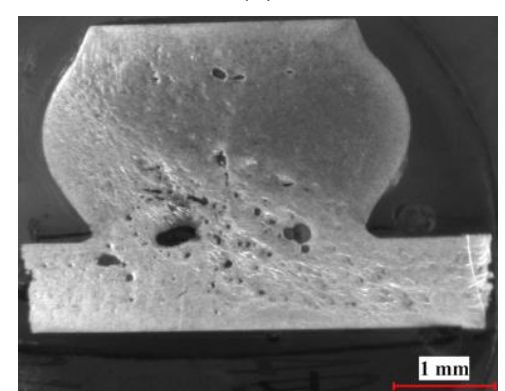

(d)

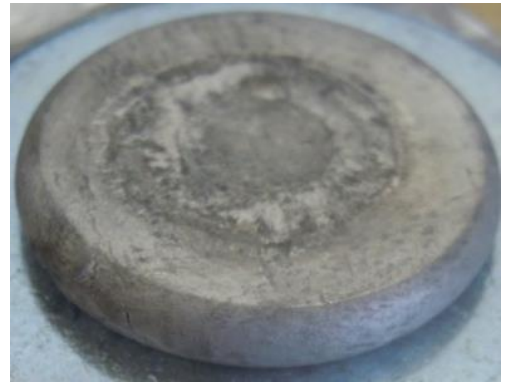

(b)

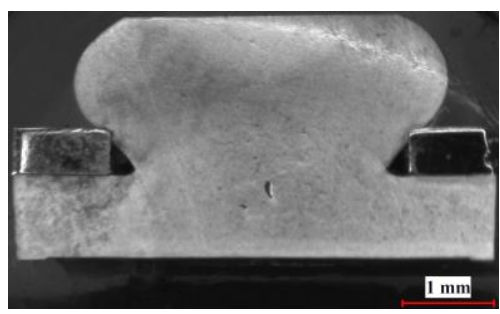

(e)

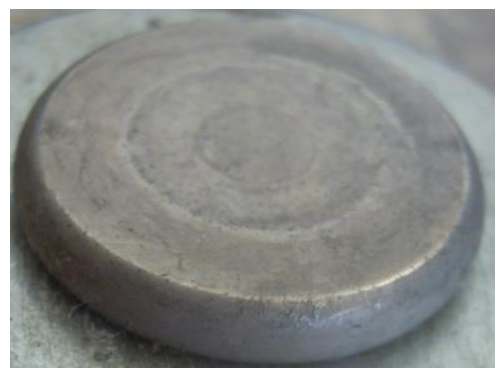

(c)

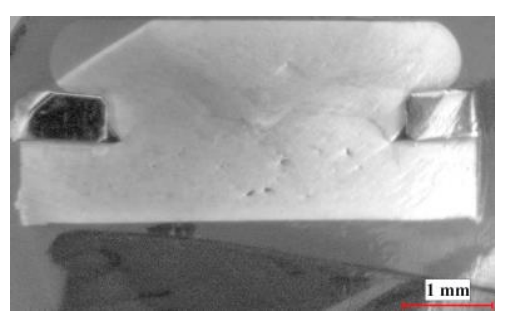

(f) 
Fig. 13. Comparison of compression rate at a heating profile of 0 to $11.5 \mathrm{kA}$ over 1.08 seconds (CSTP of $141 \mathrm{kA}^{2}$-s) compressed at a rate of (a) $21 \mathrm{~mm} / \mathrm{s}$, (b) $31.5 \mathrm{~mm} / \mathrm{s}$ and (c) $42 \mathrm{~mm} / \mathrm{s}$. The compression rate of $21 \mathrm{~mm} / \mathrm{s}$ produced consistently optimal results. AM60 protrusion heating profile of 0 to $11.5 \mathrm{kA}$ over 1.08 seconds, compressed at a rate of $21 \mathrm{~mm} / \mathrm{s}$ to distances (d) $5.5 \mathrm{~mm}$, (e) $7.5 \mathrm{~mm}$, and (f) $9.5 \mathrm{~mm}$.

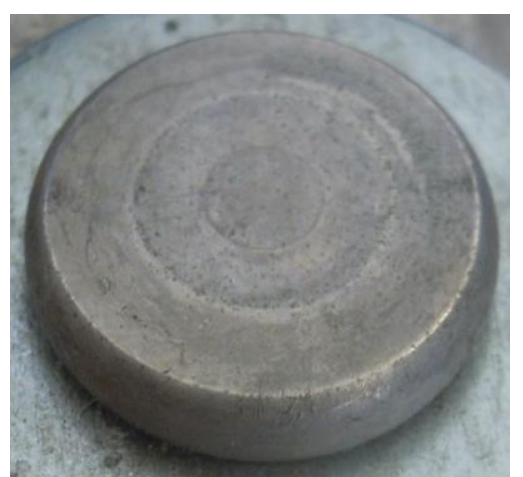

(a)

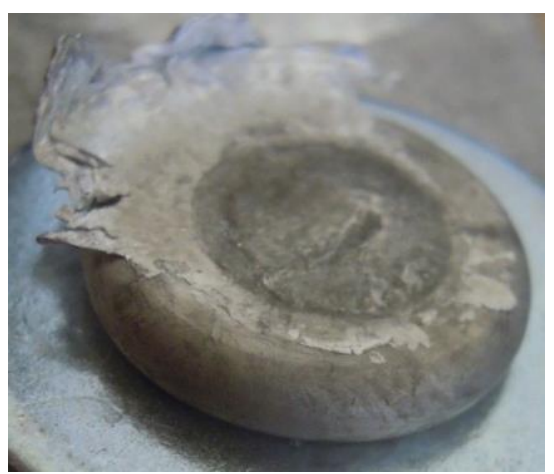

(b)

Fig. 14. Comparison of two AM60 UPJ joints produced using an applied current of 0 to $15 \mathrm{kA}$ over 0.62 seconds and compressed a compression rate (optimum rate) of $21 \mathrm{~mm} / \mathrm{s}$. Liquid magnesium formed under the top surface of the protrusion and spread laterally in the specimen shown on the right. The protrusion head, however, remained crack-free.

\subsection{Post-UPJ joint strength}

The joints were tested in lap-shear, a process commonly performed to test the strength of spot-welded joints. A vast majority of the joints reached their joint strength target as specified in the UPJ patent by FCA [22]. The post-UPJ lap shear joints failed in primarily three different ways under uniaxial tension: protrusion failure at the base, protrusion head separation, and plate failure (shown in Ref. [23]). AM60 UPJ joints, obtained as part of the experimental test matrix 2 (Taguchi), were also tested, and their Taguchi outputs are presented in Fig. 15. The failure loads were in the range of $3.1 \mathrm{kN}-6.7 \mathrm{kN}$ for most combinations of process variables (CSTP value, maximum current, and compression rate). The failure mode did exhibit some clear trends concerning the three main process variables.

Base plate fracture (12 samples out of 27) and head removal from the plate (again 12 samples out of 27) were the most common fracture modes. The remaining 3 samples exhibited internal cracking of the protrusion head. Higher peak current increased the base plate fractures, while lower maximum current resulted in head removal from the plate. The average strength of the joints as a function of failure mode was highest for plate fracture with a fracture load of 
about $5.3 \mathrm{kN}$, head removal from the plate with $4.5 \mathrm{kN}$, and head cracking internally at $4.3 \mathrm{kN}$. Based on the Taguchi matrix, the strongest joint resulted from an applied current of 0 to $9 \mathrm{kA}$ over 1.73 seconds, a CSTP of $141 \mathrm{kA}^{2}$-s and a compression rate of $42 \mathrm{~mm} / \mathrm{s}$. It is to be noted that this set of UPJ process parameters was outside of the optimal processing parameters for producing a crack-free protrusion head.

The correlation between joint strength and UPJ process parameters was rather tenuous. These experiments, in general, found hotter but more gradually (or slowly) heated protrusions resulted in stronger joints. This is likely due to cavity formation at the protrusion base where the protrusion meets the cast plate. A slowly heated protrusion to higher temperatures resulted in the area noted above becoming more ductile and formed a smoother cavity. A cooler protrusion resulted in a sharp corner at the cavity that tended to propagate a crack.

(a)
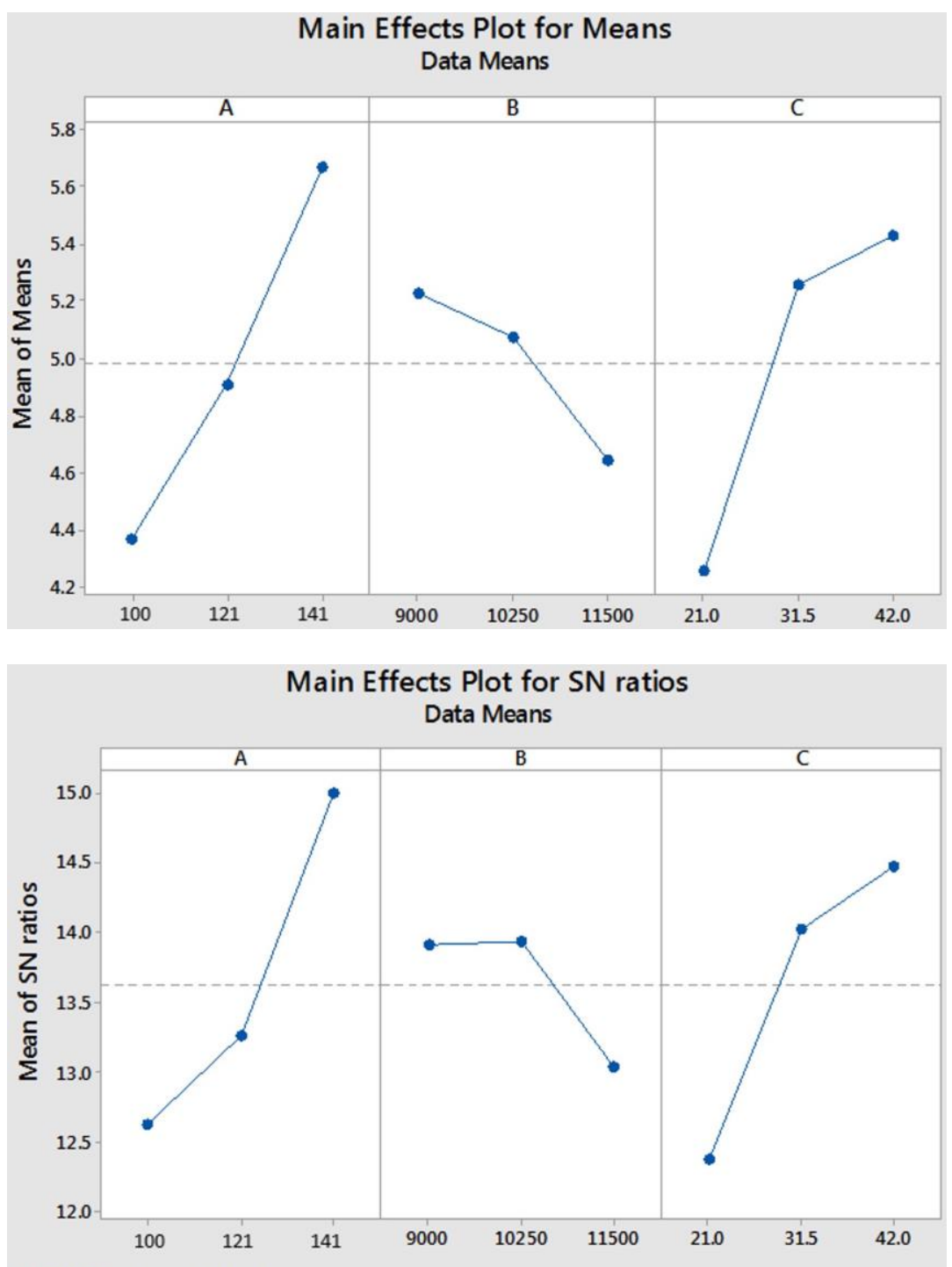

(b) Signal-to-noise: Larger is better 


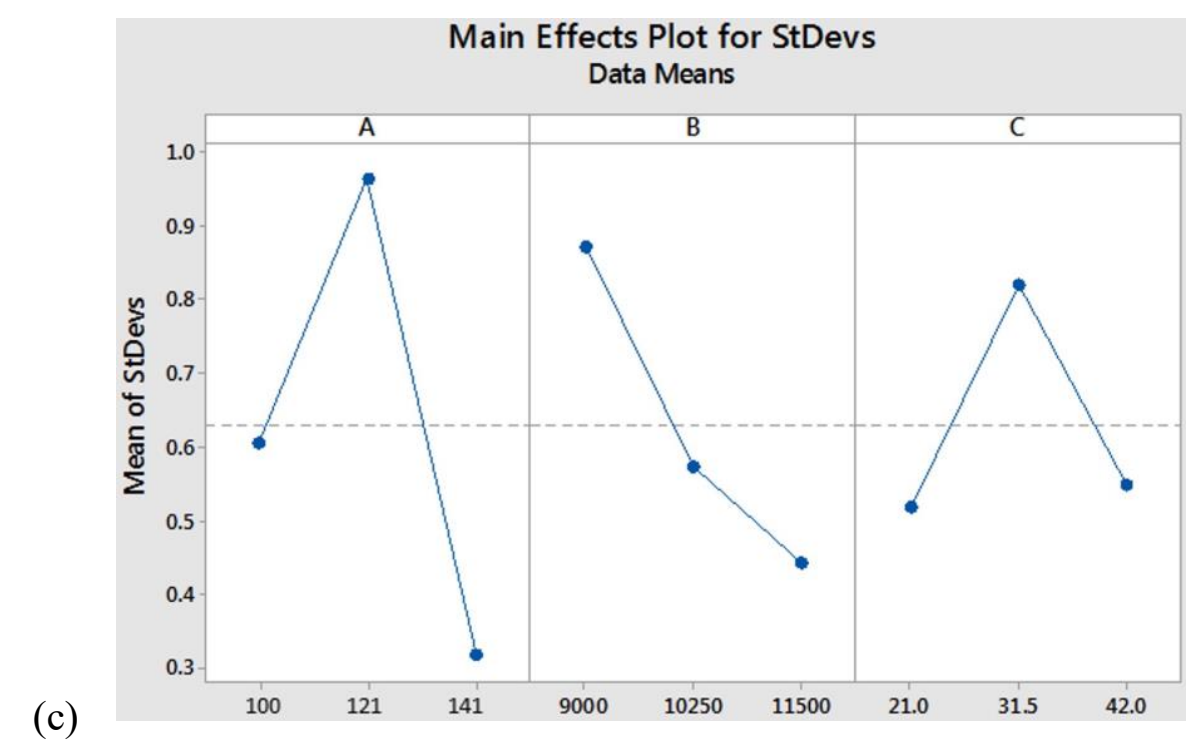

Fig. 15. Taguchi output matrix in terms of failure load. Increasing the CSTP, decreasing heating rate, and increasing the compression rate increased the maximum strength of the joint.

\subsection{Scope for future research}

While the studies related to the UPJ process were extensive, additional process parameters can be studied to assess further and expand the usefulness of the UPJ process as a method of joining. New geometries for protrusion (such as oval-shaped) and the top electrode can be considered in the future to improve heating and reducing heat losses. For example, a cylindrical protrusion with a hemispherical top can be studied to assess if it could enhance heating and reduce heat transfer (loss) to the top electrode after the current is stopped. In addition, protrusion geometries other than cylindrical, such as an oval, could prevent rotation of the sheet clamped by the UPJ joint and can be studied.

In the present study, the protrusion was heated by applying a current through a ramp function before compression. Combined profiles, such as a ramp and step, application of heat during compression, and post-UPJ heat treating are key parameters that could improve joint strength, extend UPJ to other alloys and reduce heating durations. Studies on the UPJ process can be expanded to join other non-ferrous materials which are difficult to join by welding. The UPJ process could potentially join materials such as aluminum, zinc, and steel castings. The UPJ joint strength and failure modes should be further determined under cross-tension mode as this loading mode exists during the service of an automotive component. A powerful computational method of finite element (FE) analysis could be developed to simulate the electrical resistance heating process to obtain the transient temperature field within the protrusion. Also, this temperature field can then be utilized in another FE model to simulate 
the high rate thermo-mechanical deformation of the protrusion to analyze the material flow and strain localization, damage development, and fracture characteristics. A good correlation of the model results with the experimental results greatly enhances further optimization of the UPJ process via modeling in a cost-effective manner.

\section{Conclusions}

A new laboratory-scale Upset Protrusion Joining (UPJ) process was designed and developed at McMaster University, Canada. The work presented in this paper is to evaluate the characteristics of die-cast AM60 alloy plate to join with dissimilar alloy using the UPJ process. The following conclusions are drawn from this study:

(1) A new computer-controlled upset protrusion joining (UPJ) system integrated a commercial spot-welding resistance heating system and a commercial servo-hydraulic material testing system. In this process, a cylindrical protrusion on one side of the AM60 cast plate was heated via resistance heating and then rapidly compressed (in the range of 1-2 seconds) to bond the $\mathrm{Mg}$ casting to an aluminum sheet metal plate with a hole.

(2) UPJ tests were conducted on 'load control' during pre-loading (i.e., heating stage) and then switched to 'position control' to deform the protrusion (i.e., compression). The protrusion was heated by using the ramp function (from zero to a maximum current over a duration).

(3) A new UPJ process parameter referred to as the current square time profile (CSTP) was defined. The CSTP, maximum applied current, and compression rate were considered as process variables. The UPJ experiments demonstrated 'repeatability' in both punch load versus displacement curves and joint head appearenace (visual) at given process conditions.

(4) The CSTP value (a measure of energy into protrusion) had a substantial effect on the crack formation where a lower CSTP produced surface cracks (due to the lack of dynamic recrystallization) and higher CSTP values made catastrophic failures (due to the heating beyond the eutectic temperature of AM60 alloy). An optimal value of 141 $\mathrm{kA}^{2}$-s allowed dynamic recrystallization inside the protrusion.

(5) The load increased with the increase in the compression rate. Cracks formation occurred at both lower and higher rates attributing to the heat losses to the surroundings and flow instability, respectively. Defect-free protrusion heads were obtained at compression rates of $21 \mathrm{~mm} / \mathrm{sec}$ and $31.5 \mathrm{~mm} / \mathrm{sec}$. 
(6) Perfect (good quality joints) and repeatable results were obtained at the optimum process conditions i.e., (i) $141 \mathrm{kA}^{2}$-s/15 kA, $21 \mathrm{~mm} / \mathrm{sec}$ and (ii) $141 \mathrm{kA}^{2}$-s $/ 11.5 \mathrm{kA} / 31.5$ $\mathrm{mm} / \mathrm{sec}$.

(7) Optimal process parameters obtained using Taguchi orthogonal array (optimum parameters) did not produce good joints, i.e., crack-free protrusions.

(8) The UPJ joints were tested in the lap-shear mode under uniaxial tension. For most combinations of process variables, the failure loads were in the range of $3.1 \mathrm{kN}-6.7 \mathrm{kN}$. Thus, most joints reached the target joint strength specified in the UPJ patent [22] by Fiat Chrysler Automobiles, USA.

(9) Overall, the UPJ system demonstrated its ability based on the macroscopic and microscopic responses to rapidly form UPJ joints on cast AM60 magnesium alloy in 12 seconds under a range of process conditions. Continual works are required to establish the UPJ process as a viable, robust, and cost-effective technique for dissimilar materials joining.

\section{Acknowledgements}

The authors are grateful to Dr. Sumanth Shankar of McMaster University and Mr. Steve Logan of Fiat Chrysler Automotive (FCA) for their technical support and many discussions. The authors would also like to acknowledge the technical support Mr. Ron Lodewyks, Mr. Clealand Berwick, Mr. Joe Verhaeghe, Mr. Michal Lee, Mr. John Colenbrander, and Mr. Mark MacKenzie, all part of Faculty of Engineering at McMaster University, in the design and development of UPJ system.

\section{Author Contributions}

N. Andreae: Conceptualization; Visualization; Data curation; Formal Analysis;

Investigation; Methodology; Software; Validation; Writing - original draft;

C. Dharmendra: Investigation; Writing - original draft

M.K. Jain: Conceptualization; Visualization; Investigation; Methodology; Project administration; Resources; Supervision; Writing - review \& editing.

\section{Funding}

This research was carried out and financially supported under the Automotive Partnership Canada (APC) program of Natural Science and Engineering Research Council (NSERC) of 
Canada with Dr. Sumanth Shankar of Department of Mechanical Engineering, McMaster University, as Principal Investigator.

\section{Data availability}

The raw and processed data required to reproduce the present work's findings cannot be shared at this time as the data also forms part of an ongoing study. Some data is available upon request.

\section{Declarations}

\section{Ethics approval}

This article contains research, which is original, unpublished, and has neither previously nor simultaneously been submitted anywhere else. It is not being submitted to any other journal as well.

\section{Consent to participate Not applicable \\ Consent to publish Not applicable}

Competing interest The authors declare no competing interests. 


\section{References}

[1] K.U. Kainer, H. Dieringa, W. Dietzel, N. Hort, C. Blawert, The use of magnesium alloys: Past, present and future. In Magnesium Technology in the Global Age, Proceedings of the International Symposium on Magnesium Technology in the Global Age, Montreal, QC, Canada, 1-4 October 2006; (Eds.) M.O. Pekguleryuz, L.W.F. Mackenzie; Canadian Institute of Mining, Metallurgy and Petroleum: Montreal, QC, Canada, 2006; pp. 3-19.

[2] A.A. Luo, Recent magnesium alloy development for elevated temperature applications, Inter. Mater. Rev. 49 (2004) 13-30 https://doi.org/10.1179/095066004225010497

[3] E. Schubert, M. Klassen, I. Zerner, C. Walz, G. Sepold, Light-weight structures produced by laser beam joining for future applications in automobile and aerospace industry, $\mathrm{J}$. Mater. Process. Technol. 115 (2001) 2-8. https://doi.org/10.1016/S0924-0136(01)00756-7

[4] G. Cam, M. Kocak, Progress in joining of advanced materials, Int. Mater. Rev. 43 (1998) $1-44$.

https://doi.org/10.1179/imr.1998.43.1.1

[5] G.S. Cole, A.M. Sherman, Light weight materials for automotive applications, Mater. Charact. 35 (1995) 3-9. https://doi.org/10.1016/1044-5803(95)00063-1

[6] L.H. Shah, M. Ishak, Review of research progress on aluminum-steel dissimilar welding, Mater. Manuf. Processes. 29 (2014) 928-933. https://doi.org/10.1080/10426914.2014.880461

[7] C. Dharmendra, K.P. Rao, J. Wilden, S. Reich, Study on laser welding-brazing of zinc coated steel to aluminum alloy with a zinc based filler, Mater. Sci. Eng., A 528 (2011) 1497-1503.

https://doi.org/10.1016/j.msea.2010.10.050

[8] F. Scherm, J. Bezold, U. Glatzel, Laser welding of Mg alloy MgAl3Zn1 (AZ31) to Al alloy AlMg3 (AA5754) using ZnAl filler material, Sci. Technol. Weld. Join. 17 (2012) 364-367.

https://doi.org/10.1179/136217112X13333824902080

[9] F. Liu, Z.D. Zhang, L.M. Liu, Microstructure evolution of Al/Mg butt joints welded by gas tungsten arc with Zn filler metal, Mater. Charact. 69 (2012) 84-89. https://doi.org/10.1016/j.matchar.2012.04.012 
[10] M. Gao, S. Mei, X. Li, X. Zeng, Characterization and formation mechanism of laserwelded Mg and Al alloys using Ti interlayer, Scr. Mater. 67 (2012) 193-196. https://doi.org/10.1016/j.scriptamat.2012.04.015

[11] V. Firouzdor, S. Kou, Al-to-Mg friction stir welding: effect of material position, travel speed, and rotation speed. Metall. Mater. Trans. A 41 (2010) 2914-2935. https://doi.org/10.1007/s11661-010-0340-1

[12] A.C. Somasekharan, L.E. Murr, Microstructures in friction-stir welded dissimilar magnesium alloys and magnesium alloys to 6061-T6 aluminum alloy, Mater. Charact. 52 (2004) 49-64. https://doi.org/10.1016/j.matchar.2004.03.005

[13] V. Firouzdor, S. Kou, Formation of liquid and intermetallics in Al-to-Mg friction stir welding, Metall. Mater. Trans. A 41 (2010) 3238-3251. https://doi.org/10.1007/s11661-010-0366-4

[14] Y.S. Sato, A. Shiota, H. Kokawa, K. Okamoto, Q. Yang, C. Kim, Effect of interfacial microstructure on lap shear strength of friction stir spot weld of aluminium alloy to magnesium, Sci. Technol. Weld. Join.15 (2010) 319-324. https://doi.org/10.1179/136217109X12568132624208

[15] M.J. Fernandus, T. Senthilkumar, V. Balasubramanian, S. Rajakumar, Optimizing diffusion bonding parameters in AA6061-T6 aluminum and AZ80 magnesium alloy dissimilar joints, J. Mater. Eng. Perform. 21 (2012) 2303-2315. https://doi.org/10.1007/s11665-012-0190-7

[16] D. Dietrich, D. Nickel, M. Krause, T. Lampke, M.P. Coleman, V. Randle, Formation of intermetallic phases in diffusion-welded joints of aluminium and magnesium alloys, J. Mater. Sci. 46 (2011) 357-364. https://doi.org/10.1007/s10853-010-4841-5

[17] L.M. Liu, L.M. Zhao, R.Z. Xu, Effect of interlayer composition on the microstructure and strength of diffusion bonded Mg/Al joint, Mater. Des. 30 (2009) 4548-4551. https://doi.org/10.1016/j.matdes.2009.04.040

[18] L.M. Zhao, Z.D. Zhang, Effect of Zn alloy interlayer on interface microstructure and strength of diffusion-bonded Mg-Al joints, Scr. Mater. 58 (2008) 283-286. https://doi.org/10.1016/j.scriptamat.2007.10.006

[19] J. Zhang, G. Luo, Y. Wang, Q. Shen, L. Zhang, An investigation on diffusion bonding of aluminum and magnesium using a Ni interlayer, Mater. Lett. 83 (2012) 189-191. https://doi.org/10.1016/j.matlet.2012.06.014 
[20] S.M.H. Darwish, A. Ghanya, Critical assessment of weld-bonded technologies, J. Mater. Process. Technol. 105 (2000) 221-229. https://doi.org/10.1016/S0924-0136(00)00592-6

[21] B. Chang, Y. Shi, L. Lu, Studies on the stress distribution and fatigue behavior of weldbonded lap shear joints, J. Mater. Process. Technol. 108 (2001) 307-313. https://doi.org/10.1016/S0924-0136(00)00842-6

[22] Logan SD, Langer DM (2012) Upset Protrusion Joining. US Patent US 2012/0210558 A1.

[23] N. Andreae, C. Dharmendra, M.K. Jain, Development of a laboratory-scale Upset Protrusion Joining (UPJ) system for dissimilar materials, Int J Adv Manuf Tech. 113 (2021) 2725-2738.

https://doi.org/10.1007/s00170-021-06826-9

[24] A. Buch, ASM Specialty Handbook - Magnesium and Magnesium Alloys. ASM International, Metals Park, OH. (1999) pp. 22-49.

[25] J. Mucha, L. Kaščák, E. Spišák, Joining the car-body sheets using clinching process with various thickness and mechanical property arrangements, Archieves of Civil and Mechanical Engineering, 11 (2011) 135-148. https://doi.org/10.1016/S1644-9665(12)60179-4

[26] N. Logothetis, H.P. Wynn, Quality Through Design: Experimental Design, Off-line Quality control, and Taguchi's Contributions, Oxford University Press, Oxford Science Publications, (1990) ISBN 0-19-851993-1; https://doi.org/10.1002/qre.4680060217

[27] C. Dharmendra, K.P. Rao, Y.V.R.K. Prasad, N. Hort, K.U. Kainer, Hot working mechanisms and texture development in $\mathrm{Mg}-3 \mathrm{Sn}-2 \mathrm{Ca}-0.4 \mathrm{Al}$ alloy, Mater. Chem. Phys. 136 (2012) 1081-1091.

https://doi.org/10.1016/j.matchemphys.2012.08.054

[28] C. Dharmendra, M.K. Jain, S. Shankar, F. Fazeli, Workability characteristics and deformation mechanisms of die-cast AM60 and AZ91 magnesium alloys: Correlation with processing maps, J. Mater. Engg. Perf. 28 (2019) 123-139. https://doi.org/10.1007/s11665-018-3745-4

[29] A.A. Luo, C. Zhang, A.K. Sachdev, Effect of eutectic temperature on the extrudability of magnesium-aluminum alloys, Scr. Mater. 66 (2012) 491-494. https://doi.org/10.1016/j.scriptamat.2011.12.025 